\title{
$1 \quad$ LST-1 acts in trans with a conserved RNA-binding protein to maintain stem cells
}

3 Kimberly A. Haupt ${ }^{1}$, Amy L. Enright ${ }^{1 *}$, Ahlan S. Ferdous ${ }^{1 *}$, Aaron M. Kershner ${ }^{2,3}$, Heaji Shin ${ }^{1,4}$, Marvin

$4 \quad$ Wickens ${ }^{1}$ and Judith Kimble ${ }^{1,2,5}$

* These authors contributed equally to this work

${ }^{1}$ Department of Biochemistry and ${ }^{2}$ Howard Hughes Medical Institute, University of Wisconsin-Madison,

9 Madison, Wisconsin, 53706, USA.

$10{ }^{3}$ Present Address: Department of Urology, Stanford University School of Medicine, Stanford, CA, USA.

$11{ }^{4}$ Present Address: The David H. Koch Institute for Integrative Cancer Research, MIT, Cambridge, MA

12 02139, United States

13

$14{ }^{5}$ Correspondence should be addressed to:

\section{IMPACT STATEMENT}

25 A key stem cell regulator partners with a broadly conserved PUF RNA-binding protein to drive self-

26 renewal and maintain a stem cell pool. 


\section{ABSTRACT}

29 Stem cell self-renewal is essential to development and tissue repair. The $C$. elegans LST-1 protein is a

30 pivotal regulator of self-renewal and oncogenic when misexpessed. Here we define regions within the

31 LST-1 protein that provide molecular insights into both its function and regulation. LST-1 self-renewal

32 activity resides within a predicted disordered region that harbors two KXXL motifs. These KXXL motifs

33 mediate LST-1 binding to FBF, a broadly conserved Pumilio/PUF RNA-binding protein that represses

34 differentiation. Point mutations of the KXXL motifs abrogate LST-1 self-renewal activity. Therefore, FBF

35 binding is essential to LST-1 function. A second distinct region regulates LST-1 spatial expression and

36 primarily affects LST-1 protein turnover. Upon loss of this regulatory region, LST-1 protein distribution

37 expands and drives formation of a larger than normal GSC pool. Thus, LST-1 promotes self-renewal as a

38 key FBF partner, and its spatial regulation helps determine size of the GSC pool.

INTRODUCTION

A central paradigm in stem cell biology is that niche signaling regulates key target genes to promote

42 self-renewal. Examples of niches and niche signaling pathways abound (e.g. Lander et al., 2012), but

43 direct targets of niche signaling - the key genes activated in stem cells to drive self-renewal - have, for

44 the most part, been elusive, with a handful of exceptions. One such is the myc gene, a target of Notch,

45 BMP and Wnt signaling in mammalian stem cells (Moore \& Lemischka, 2006). Another is the Ist-1 (lateral

46 signaling target-1) gene, a target of GLP-1/Notch signaling in nematode germline stem cells (GSCs)

47 (Figure 1A) (Kershner, Shin, Hansen, \& Kimble, 2014; Lee, Sorensen, Lynch, \& Kimble, 2016). The LST-1

48 protein stands out as essential for self-renewal, and acts redundantly with another target of niche

49 signaling, SYGL-1 (Kershner et al., 2014). LST-1 protein is normally restricted to the GSC pool region but

50 becomes oncogenic when ubiquitously expressed (Shin et al., 2017). While the biological significance of 
51 LST-1 is unambiguous, the challenge now is to understand, in molecular terms, how LST-1 executes its

52 key role in stem cell self-renewal and how it is regulated.

LST-1 has been proposed to work in a macromolecular complex with PUF RNA-binding proteins, FBF-

1 and FBF-2 (collectively FBF), to repress differentiation-promoting RNAs (Figure 1B) (Shin et al., 2017).

55 This idea is based on several lines of evidence. First, LST-1 harbors a predicted Nanos-like zinc finger

56 (Kershner et al., 2014) (Figure 1D) and the protein is cytoplasmic and granular (Shin et al., 2017), both

57 consistent with a role in RNA regulation. Second, LST-1 interacts in yeast with FBF-1 and FBF-2 (Shin et

58 al., 2017). Third, LST-1 cannot form tumors in the absence of FBF, suggesting that its self-renewal

59 activity is dependent on FBF (Shin et al., 2017). Finally, LST-1 contributes to the repression of gld-1, an

established FBF target mRNA in GSCs (J. L. Brenner \& Schedl, 2016; Shin et al., 2017). While the model is

61 attractive, it has not yet been tested in vivo in nematodes, nor is it known whether LST-1 must directly

62 bind FBF to exert its self-renewal activity.

LST-1 spatial restriction to the GSC pool region suggested that the extent of Ist-1 expression might

65 expression of full-length LST-1 throughout the germline drove formation of a tumor. One established regulator of Ist-1 expression in the distal germline is Notch signaling, which activates Ist-1 transcription

67 within the niche (Kershner et al., 2014; Lee et al., 2016). However, virtually nothing was known prior to

68 this work about how LST-1 protein is spatially restricted to the GSC pool region.

The LST-1 amino acid sequence provided few clues to the molecular basis of its self-renewal activity

70 or its regulation (Kershner et al., 2014). Here we identify one LST-1 region sufficient for stem cell self-

71 renewal and another required for spatial regulation. Within the self-renewal region, we find two short

72 sequence motifs that mediate directly binding to FBF and are essential for LST-1 self-renewal activity.

73 Within the regulatory region, we find that the Nanos-like zinc finger is central to spatial regulation: upon

74 loss of this region, the distribution of LST-1 protein expands, leading to formation of a larger than 
normal GSC pool. Thus, LST-1 drives self-renewal as a key FBF partner, and its spatial regulation helps determine size of the GSC pool.

\section{RESULTS}

\section{LST-1L isoform is critical for self-renewal}

The Ist-1 locus encodes two transcripts, predicted to generate two proteins, a longer LST-1L and

81 shorter LST-1S (Figure 1D) (Kershner et al., 2014). The LST-1L and LST-1S amino acid sequences overlap

82 extensively and harbor multiple predicted intrinsically disordered regions (IDRs; regions with a high

83 proportion of polar and charged amino acids and a low proportion of nonpolar amino acids (Dyson,

84 2016)) and a CCHC Nanos-like zinc finger (Figure 1D; Supplementary Figure S1A) (Kershner et al., 2014).

85 To differentiate between the roles of LST-1L and LST-1S, we compared the self-renewal activities of wild-

86 type LST-1 (Figure 1E) to a mutant predicted to make only LST-1S (Figure 1F). This mutant, termed Ist-1

87 (frameshift), is a single base pair deletion in the Ist-1L start codon should abolish production of LST-1L

88 but leave LST-1S intact. For protein visualization, both Ist-1-wild-type(wt) and Ist-1(fs) carried a V5

89 epitope tag at the shared C-terminus (Figure 1E, 1F), which we indicate henceforth in superscript.

90 We assayed self-renewal activity of the $I s t-1(f s)^{v 5}$ mutant and $I s t-1(w t)^{15}$ in a sygl-1 mutant

91 background, where LST-1 is strictly required for GSC maintenance (Kershner et al., 2014). Previous

92 studies showed that virtually $100 \%$ of $I s t-1(w t)^{v 5}$ animals made a healthy fertile germline in the absence

93 of SYGL-1, whereas strong loss-of-function Ist-1 mutants were $100 \%$ sterile with no GSCs

94 (Supplementary Figure S1B) (Kershner et al., 2014; Shin et al., 2017). Here we confirm that Ist-1(wt)

95 supports fertility, but find that $I s t-1(f s)^{v 5}$ is $100 \%$ sterile with no GSCs in the absence of SYGL-1 (Figure

$96 \mathbf{1 E}, \mathbf{1 F}$, Supplementary Figure S1B). By this simple assay, the $I s t-1(f s)^{v 5}$ mutant phenotype is consistent

97 with a strong loss-of-function. By western blot, we confirmed that LST-1L expression is nearly eliminated

98 in $I s t-1(f s)^{v 5}$, while the LST-1S isoform remains expressed (Figure 1I). We finally used an $\alpha-V 5$ antibody to 
99 stain $I s t-1(w t)^{v 5}$ and $I s t-1(f s)^{v 5}$ gonads and found similar spatially restricted staining in both

100 (Supplementary Figure S1C-F). We conclude that LST-1L is necessary for GSC self-renewal activity, and

101 that LST-1S not sufficient for activity despite expression in GSCs.

102 Consistent with its functional role in GSC self-renewal, we expected the LST-1L isoform to be

103 expressed in GSCs. To test this idea, we introduced an epitope tag at the unique LST-1L N-terminus to

104 visualize this isoform specifically. For this experiment, we used a FLAG tag because attempts to insert V5

105 at the $\mathrm{N}$-terminus failed. We call the allele $I s t-1(L)^{\text {FLAG }}$ (Figure 1G). As a control, we generated Ist-

$1061(L / S)^{F L A G}$ by inserting the FLAG tag at the shared C-terminus to visualize LST-1L and LST-1S collectively

107 (Figure 1 H). Both N-terminal and C-terminal Ist-1 ${ }^{F L A G}$ variants maintained GSCs in the absence of SYGL-1

108 and therefore were functional (Fig 1G,H; Supplementary Figure S1B). Upon immunostaining, both LST-

$1091(\mathrm{~L})^{\mathrm{FLAG}}$ and $\mathrm{LST}-1(\mathrm{~L} / \mathrm{S})^{\mathrm{FLAG}}$ were expressed in the GSC region of the distal germline with similar

110 subcellular localization (Figure 1J, 1K). We conclude that the LST-1L isoform is present in GSCs and that it

111 harbors self-renewal activity.

\section{$113 \mathrm{~N}$-terminal LST-1 fragment is sufficient for stem cell maintenance}

114 To delineate the region within LST-1 required for self-renewal activity, we generated a series of Ist-1

115 variant alleles (Figure 2). Each was introduced into the $I s t-1(w t)^{v 5}$ locus (Figure 2A). Because all Ist-1

116 variants from this point carry the V 5 tag, for simplicity we henceforth omit the V 5 superscript in allele

117 designations. In addition, we show only LST-1L diagrams for simplicity and because LST-1L is the primary

118 isoform with self-renewal activity. To serve as a control, we also created an Ist-1( $\varnothing$ ) protein null mutant

119 by deleting the entire open reading frame at the endogenous locus (Figure 2B). As expected (Kershner

120 et al., 2014; Shin et al., 2017), all Ist-1(ø) homozygotes maintained GSCs in the presence of SYGL-1 due

121 to redundancy, but none maintained GSCs in the absence of SYGL-1 (Figure 2F, Supplementary Figure

122 S2A). 
To test Ist-1 variants for function in vivo, each allele was assayed for GSC maintenance in the

124 presence and absence of SYGL-1. Two variants that retained N-terminal regions, Ist-1(1-210) and Ist-1(1-

125 152), were able to maintain GSCs in the absence of SYGL-1 (Figure 2C, 2D, Supplementary Figure S2A).

126 Therefore, they both harbor self-renewal activity. Complementary alleles with C-terminal parts of the

127 protein, Ist-1(211-328) and Ist-1(153-328), were unable to maintain GSCs (Figure 2E, 2F, Supplementary

128 Figure S2A) (see Figure 4 and Supplementary Figure S5 for confirmation of germline expression).

129 Analogous transgenic experiments performed prior to the CRISPR/Cas9 revolution gave the same results

130 (Supplementary Figure S2B-E). Finally, although the truncation experiments showed that the zinc finger

131 was dispensable for self-renewal, we explored this domain specifically by mutating two cysteine

132 residues required for its architecture (Hashimoto et al., 2010; Weidmann et al., 2016). The Ist-1(C260S

133 C263S) missense mutant, dubbed Ist-1(ZnF), maintained GSCs in the absence of SYGL-1, like full length

134 Ist-1(wt) and the fragments Ist-1(1-210) and Ist-1(1-152). This confirms that the zinc finger is not critical

135 for GSC maintenance (Figure 2G). We conclude that LST-1 self-renewal activity resides in the N-terminal

136 half of the protein.

137 Interestingly, while both Ist-1(1-210) and Ist-1(1-152) function properly for GSC self-renewal, these

138 two variants differ with respect to the hermaphrodite sperm/oocyte switch: $100 \%$ of the Ist-1(1-210)

139 animals made the switch and were self-fertile in the absence of SYGL-1, while none of the Ist-1(1-152)

140 animals made the switch and instead had a sterile Mog (Masculinization of Germline) phenotype

141 (Supplementary Figure S2A). A role for LST-1 in the sperm/oocyte decision was known: indeed, we note

142 that even with SYGL-1 present, a few Ist-1( $\varnothing)$ homozygotes $(\leq 5 \%)$ failed to make the sperm-to-oocyte

143 switch and had a Mog phenotype (Supplementary Figure S2A), as previously shown for two other Ist-1

144 strong loss-of-function alleles (Kershner et al., 2014; Shin et al., 2017). This LST-1 effect on germline sex

145 determination likely reflects the common molecular basis for regulation of germline self-renewal and

146 germline sex determination as both rely on FBF RNA regulation (Sarah L. Crittenden et al., 2002; Zhang 
147 et al., 1997). Yet for the purposes of this study, we focus on LST-1 regulation of GSC maintenance via its

$148 \quad$ N-terminal half.

\section{Two FBF binding motifs are essential for LST-1 self-renewal activity}

151 We next sought to identify the molecular function of the N-terminal half of LST-1. LST-1 was

152 proposed to function with FBF RNA-binding proteins to achieve self-renewal (see Introduction), two

153 other FBF partners, CPB-1 and GLD-3, possess a consensus KTXL motif critical for FBF binding, where $\mathrm{X}$ is

154 any amino acid (Figure 3A) (Menichelli, Wu, Campbell, Wickens, \& Williamson, 2013; Wu, Campbell,

155 Menichelli, Wickens, \& Williamson, 2013). We therefore scanned the LST-1(1-152) fragment for a similar

156 KTXL FBF-binding motif. Although no KTXL motif was found, we did find two similar sequences: KQLL

157 (amino acids 32-35) and KLHL (amino acids 80-83). Both are conserved across Caenorhabditids

158 (Supplementary Figure S4A), and we dub them A and B respectively (Figure 3B, Supplementary Figure

159 S1A). Intriguingly, not only do these A and B sites reside in the N-terminal half of LST-1, they are also in

160 the LST-1L-specific region.

161 We first tested A and B for FBF binding in yeast (Supplementary Figure S3A). Because full length,

162 wild-type LST-1 bound to FBF-1 and FBF-2 similarly in a yeast two-hybrid assay (Shin et al., 2017), we

163 used FBF-2 for this work. We first found that full length LST-1(wt) and LST-1(1-152) interacted similarly

164 with FBF-2 in yeast (Supplementary Figure S3B) and therefore focused on LST-1(1-152) for subsequent

165 assays. To test the importance of the A and B sites, we mutated their first and fourth positions to

166 alanine (Figure 3C, Supplementary Figure S3B). Mutation of A had no appreciable effect on the yeast

167 interaction, mutation of $B$ reduced the interaction, and mutation of $A$ and $B$ in the same fragment

168 abolished the interaction (Figure 3C, Supplementary Figure S3B), both in yeast growth assays

169 (Supplementary Figure S3C) and $\beta$-gal assays (Supplementary Figure S3D). We conclude that the LST-1 
170 self-renewal fragment has two FBF interaction motifs, and that at least in yeast, the B motif is

171 quantitatively more important than the A motif.

172 To probe the biological significance of the LST-1 A and B sites in nematodes, we engineered point

173 mutations in the two KXXL motifs at the Ist-1 endogenous locus, both individually and together (Figure

174 3D). The nematode $B$ motif mutation was identical to that made in yeast (K80A L83A), but the

175 nucleotide sequence encoding the A motif straddles an intron (Figure 3B, top), making simultaneous

176 mutation of both K32 and L35 challenging. Because the leucine at the fourth position stood out as

177 critical for CPB-3 and GLD-3 interactions with FBF (Menichelli et al., 2013), we chose to disrupt L35 alone

178 to test the importance of the A motif in nematodes. We introduced the mutations into the Ist-1(wt) $)^{v 5}$

179 locus (Figure 3D) and generated three alleles, Ist-1(A)[L35A], Ist-1(B)[K80A L83A] and Ist-1(AB)[L35A

$180 K 80 A$ L83A]. All were fertile and healthy when SYGL-1 was present (Figure 3D, 3E, 3H for Ist-1(AB);

181 Supplementary Figure S4B).

182 To assay the importance of the A and B sites for GSC self-renewal, each of the three mutants was

183 tested in the absence of SYGL-1. Both $I s t-1(A)$ and $I s t-1(B)$ maintained GSCs and were fertile (Figure 3D,

184 Supplementary Figure S4B). In striking contrast, Ist-1(AB) did not maintain GSCs: we observed a strong

185 GSC defect characterized by self-renewal failure and the premature differentiation to sperm in an early

186 larval stage (Figure 3D, 3F, 3H, Supplementary Figure S4B). This phenotype was dramatic, and

187 indistinguishable from that of $I s t-1(\varnothing)$ sygl-1( $\varnothing)$ (Figure 3F, 3G, 3H). Thus, Ist-1(AB) has lost its self-

188 renewal activity. Importantly, the LST-1(AB) protein was present with an abundance and distribution

189 similar to LST-1(wt) (Figure 3I-3K). Therefore, LST-1(AB) protein is expressed normally, but unable to

190 promote self-renewal. We conclude that LST-1 depends on its two KXXL FBF binding motifs for self-

191 renewal activity.

192 
193 The C-terminal region controls spatial restriction

194 We next examined the Ist-1 variants for more subtle effects on GSC maintenance. To this end, we

195 assayed size of the progenitor zone (PZ) in all of our variants (Figure 4A), because the PZ size may reflect

196 the position of the regulatory network switch from stem cell state to differentiation (Sarah L. Crittenden,

197 Leonhard, Byrd, \& Kimble, 2006). PZ measurements were collected in the presence of wild-type SYGL-1

198 to ensure healthy germline size and organization. Most variants had a PZ size similar to wild-type (Figure

199 4B). Unexpectedly however, the PZ size was larger than wild-type for Ist-1(1-210) and Ist-1(ZnF) (Figure

200 4B).

201 We reasoned that the longer PZs in Ist-1(1-210) and Ist-1(ZnF) might result from an aberrant

202 expansion of LST-1 spatial expression. To test this idea, gonads dissected from selected variants were

203 immunostained with an $\alpha$-V5 antibody; wild-type SYGL-1 was again present to ensure robust germline

204 size and organization. LST-1(wt) protein was restricted to the same distal germline region reported

205 previously (Shin et al., 2017) (Figure 4C). By contrast, LST-1(1-210) and LST-1(ZnF) were both more

206 abundant and their expression extended more proximally than wild-type (Figure 4D, 4F). LST-1(211-328)

207 was of lower abundance (Figure 4E). Ist-1( $\varnothing$ ) does not carry a V5 tag and so provided a negative control

208 where no staining was observed (Figure 4G). To quantify protein abundance as a function of position

209 within the distal gonad, we generated Z-projections $(n \geq 5)$ from at least three independent experiments.

210 We used Fiji/ImageJ to score LST-1 abundance along the gonadal axis (see Methods for details).

211 Quantitation confirmed that LST-1(1-210) and LST-1(ZnF) proteins were more abundant and extended

212 further proximally than LST-1(wt) (Figure 4H). This altered expression pattern offers a likely explanation

213 for the enlarged PZ in the two mutants.

214 The increased abundance of LST-1(1-210) and LST-1(ZnF) proteins could be due to increased Ist-1

215 mRNA stability, increased translation or changes in LST-1 protein turnover. To query the abundance of

216 Ist-1 mRNAs, we performed single molecule fluorescence in situ hybridization (smFISH) with probes 
217 designed against sequences that were intact and identical in the three variants tested but absent in the

218 control (Figure 5A). The result was striking: Ist-1 RNAs in Ist-1(wt), Ist-1(1-210) and Ist-1(ZnF) were all

219 restricted to the distal-most 4-5 rows of germ cells and absent in the Ist-1( $\varnothing$ ) control (Figure 5B-E). LST-1

220 protein expansion was therefore not due to a coordinate expansion of RNAs. Curiously, quantitation

221 revealed that Ist-1(1-210) and Ist-1(ZnF) RNAs were modestly more abundant ( $30 \%$ higher) than Ist-

2221 (wt) RNA (Figure 5F, 5G), suggesting that the LST-1 zinc finger has a minor autoregulatory effect on Ist-

2231 mRNA abundance. Together, these quantitative analyses of Ist-1 RNA and protein indicate that the

224 LST-1 C-terminal region mediates two distinct regulatory activities: the zinc finger downregulates Ist-1

225 RNA abundance, and a broader region, yet to be defined but including the zinc finger, downregulates

226 LST-1 protein abundance and controls extent, likely through an effect on protein turnover (see

227 Discussion).

Spatial extent of LST-1 determines GSC pool size shift in the regulatory network from self-renewal to differentiation. To this end, we conducted emb-30 assays (Figure 6A) (Cinquin, Crittenden, Morgan, \& Kimble, 2010). Briefly, this assay blocks the cell cycle

233 and stops proximal cell migration through the progenitor zone so that germ cells reveal their naïve or

234 differentiated state in situ (see legend for more detail). It is the only functional assay available for GSC

235 pool size, and we interpret the results to be a rough estimate of the number of GSCs made in each strain

236 tested. We focused on Ist-1(wt) and Ist-1(1-210) for this experiment, and tested both CRISPR-induced

237 LST-1 variants at the endogenous locus (Figure $\mathbf{2 A}, \mathbf{2 C}$ ) as well as single-copy transgenic variants inserted

238 at a MosSCI site (Supplementary Figure S2B, S2C). While the LST-1 fragments assayed were identical,

239 two critical differences existed between these experiments for historical reasons. First, the endogenous

240 alleles were assayed in a sygl-1( $\varnothing$ ) background so that GSCs were dependent on LST-1 alone, while 
241 transgenes were assayed in an $I s t-1(\varnothing)$ sygl-1(+) background so that all LST-1 protein came from the

242 transgenic allele. Second, the endogenous alleles were tagged with V5 while transgenes were tagged

243 with HA. Remarkably, these two experiments gave virtually the same result: Ist-1(wt) possessed an

244 average of $\sim 40$ germ cells in its GSC pool, whereas lst-1(1-210) had an average of $\sim 55-75$ (Figure 6B).

245 Thus, Ist-1(1-210) makes a significantly larger GSC pool than Ist-1(wt) (Figure 6B). Our results indicate

246 that LST-1 extent modulates size of the GSC pool.

247 To further interrogate the potency of the LST-1(1-210) protein for GSC maintenance, we assayed its

248 effect when ubiquitously expressed. This assay was essentially the same as done earlier with the full

249 length LST-1(wt) protein, which makes a massive germline tumor when placed under control of a

250 ubiquitous germline promoter, mex-5, and the tbb-2 3'UTR (Shin et al., 2017). To ask if LST-1(1-210)

251 might be similarly oncogenic, we made an analogous transgene, placing LST-1(1-210) under the same

252 regulatory elements (Figure 6C). The strain was created and maintained with Ist-1(RNAi) to prevent

253 expression of the potentially oncogenic LST-1. Upon removal from Ist-1(RNAi), ubiquitous LST-1(1-210)

254 drove formation of germline tumors that were composed of mitotically dividing cells, as evidenced by

255 M-phase nuclear morphology and PH3-marked cells (Figure 6D). We conclude that ubiquitous LST-1(1-

256 210) mimics LST-1(wt) in its oncogenicity. Furthermore, our data reveal that expression of LST-1(1-210)

257 tunes the GSC pool size, and LST-1 downregulation is required to facilitate the molecular switch from

258 stem cell state to differentiation (Figure 6E, 6F, 6G).

\section{DISCUSSION}

261 C. elegans LST-1 provides a major molecular link between niche signaling and effectors of stem cell

262 self-renewal (Kershner et al., 2014; Shin et al., 2017). Here we establish the key features of its

263 mechanism of action at a molecular level. The LST-1 N-terminal half is responsible for self-renewal. The

264 C-terminal half is responsible for spatial restriction of the protein in the distal germline (Figure 7A). 
265 Additional analyses of each region reveal critical aspects of the LST-1-FBF molecular complex and its

266 control of stem cell fate.

267

\section{Dual FBF binding motifs may afford plasticity}

The LST-1 N-terminal half and self-renewal region harbors two small linear motifs that mediate FBF

binding, the KXXL motif. Each of these two motifs has biological activity in nematodes: LST-1 self-

271 renewal activity remains intact when either motif is mutated, but when both are mutated, self-renewal

272 activity is lost. The discovery of two motifs was unexpected, because other FBF partners GLD-3 and CPB-

2731 possess only a single KXXL motif (Campbell et al., 2012; Menichelli et al., 2013; Wu et al., 2013). The

274 two LST-1 motifs are conserved throughout the Caenorhabditids (Supplementary Figure S4A),

275 suggesting biological significance.

276 The existence of two KXXL motifs may afford plasticity to the LST-1-FBF complex. We do not yet

277 know where within FBF these motifs bind but clues are available. The motifs in GLD-3 and CPB-1 interact

278 in vitro at the loop between PUF repeats 7 and 8, dubbed the R7/8 loop (Menichelli et al., 2013; Wu et

279 al., 2013). By analogy, the dual LST-1 motifs may each be able to bind the same loop. Indeed, a purified

280 fragment harboring one LST-1 motif, called in this work the B site, binds to the R7/8 loop in the crystal

281 structure of an FBF-2/LST-1B-site/RNA complex (C. Qiu, personal communication, May 2019). However,

282 the LST-1 A and B motifs are unlikely to bind the same site simultaneously, raising the possibility that

283 these dual motifs provide other opportunities. For example, some LST-1-FBF complexes may rely on the

284 A site binding to the R7/8 loop (Figure 7B), while others rely on B site binding to the same loop (Figure

285 7C). This scenario introduces the possibility of considerable plasticity in the regulation and molecular

286 configuration of the two complexes. Alternatively, the dual motifs may bind at distinct sites in FBF

287 (Figure 7D). More radically, they may link two FBF proteins together, with LST-1 binding at each of their

288 R7/8 loops. These various scenarios have important implications for configuration, stability and 
regulation of this critical FBF-LST-1 partnership and thus for FBF combinatorial control of RNAs and stem

290 cell self-renewal.

\section{LST-1 self-renewal activity: a series of IDRs that work in trans with FBF}

The LST-1 self-renewal region possesses two FBF-binding motifs A and B plus a series of sequences

predicted to be intrinsically disordered. The LST-1(1-152) variant contains three intrinsically disordered

295 regions (IDRs), and LST-1(1-210) has four (Figure 7A). Therefore, LST-1 is a trans-acting protein that

296 brings a stretch of IDRs to FBF (Figure 7E). IDRs are commonly found in RNA-binding proteins (Calabretta

297 \& Richard, 2015) and implicated in diverse steps of RNA regulation: splicing (Chen \& Moore, 2014),

298 decapping (Jonas \& Izaurralde, 2013), deadenylation (Webster, Stowell, \& Passmore, 2019) and RNP

299 granule formation (Mittag \& Parker, 2018; Uversky, 2017). However, IDRs in RNA-binding proteins act

300 within the same polypeptide and hence in cis with the RNA-binding domain. The LST-1 IDRs, by contrast,

301 are not in the same polypeptide as FBF and hence work in trans.

302 The LST-1 trans activity could act through a range of mechanisms (Figure 7E). However, we suggest

303 that LST-1 IDRs, or perhaps not-yet-identified small linear motifs interspersed within the IDRs, stabilize

304 the formation of a complex that represses target mRNAs. Our thinking is guided by three previous

305 studies. First, FBF binding elements regulate poly(A) tail length (Ahringer \& Kimble, 1991). Second, FBF,

306 like other PUF proteins, interacts in vitro with the CCR4-Not deadenylase complex (Suh et al., 2009),

307 suggesting that FBF represses RNAs, at least in part, via deadenylation. Third, LST-1 promotes

308 destabilization of an FBF target mRNA in vivo (Shin et al., 2017), suggesting that it works with FBF to

309 promote deadenylation. Indeed, yeast Puf3 (yPuf3), a PUF RNA-binding protein from S. cerevisiae,

310 possesses an N-terminal tail composed largely of IDRs and critical for interactions with the CCR4-Not

311 complex. Remarkably, the longer the yPuf3 tail and hence larger the number of its IDRs, the greater the

312 deadenylase activity in vitro (Webster et al., 2019) (Figure 7F). We suggest that the trans-acting LST-1 
313 protein may work similarly to stabilize the interaction with an effector protein or complex (Figure 7G).

314 The CCR4-Not complex is a strong candidate because of its in vitro interaction with FBF (Suh et al.,

315 2009). Other possibilities exist and they are not mutually exclusive. For example, LST-1 may prevent

316 recruitment of a positive-acting regulatory factor, such as the GLD-2/GLD-3 poly(A) polymerase (L.

317 Wang, Eckmann, Kadyk, Wickens, \& Kimble, 2002). Regardless, the discovery of an IDR-rich fragment

318 that works in trans with an RNA-binding protein suggests broad, new avenues for combinatorial control.

LST-1 downregulation and the molecular switch from stem cell state to differentiation

Spatial regulation of LST-1 in the distal germline is tight and biologically significant. Normally, Ist-1

322 mRNA and LST-1 protein are restricted to a germline region corresponding roughly to the GSC pool

323 (Kershner et al., 2014; Shin et al., 2017, this work). By contrast, ubiquitous LST-1 expression drives

324 formation of a germline tumor (Shin et al., 2017). We have found two LST-1 variants with a modest

325 expansion in protein expression. One variant, LST-1(1-210), is a truncation fragment that lacks the C-

326 terminal 128 amino acids; the other is a missense mutant that disrupts structural residues in the LST-1

327 Nanos-like zinc finger (ZnF). Both lack a functional ZnF, but LST-1(1-210) lacks additional regions as well.

328 LST-1(1-210) and LST-1(ZnF) are more abundant and expand more proximally in the distal germline than

329 LST-1(wt), and therefore must lack critical regions or residues controlling normal spatial regulation of

330 the protein. As a result, we observe a delay in the switch from the stem cell state to differentiation: both

331 variants increase the size of the progenitor zone (Figure 4B) and LST-1(1-210) increases size of the GSC

332 pool (Figure 6B, 6D). Thus, downregulation of LST-1 protein is essential for proper cell fate

333 determination and the switch between stem cell state and differentiation (Figure 6E).

334 The primary mechanism of LST-1 downregulation is likely via regulated protein instability. The RNAs

335 encoding LST-1(1-210) and LST-1(ZnF) were restricted spatially as in wild-type, but the proteins were

336 dramatically expanded (Figure 5G). Germ cells move proximally at a rate of about one cell per hour in 
337 the distal gonad (Rosu \& Cohen-Fix, 2017), which provides a useful space-time axis. Wild-type Ist-1 RNA

338 and LST-1 protein disappear at about the same place along this axis (Shin et al., 2017, this work),

339 suggesting that they are both normally regulated tightly and are unstable. By contrast, LST-1(1-210) and

340 LST-1(ZnF) proteins disappear hours later than their RNAs, with time measured by position along the

341 axis. This change in protein turnover was particularly noticeable with LST-1(1-210). Therefore, loss of the

342 Zn finger affects LST-1 stability, but loss of the C-terminal third is more dramatic. Earlier studies found

343 that decreased proteasome activity leads to increased germline proliferation (Gupta et al., 2015;

344 Macdonald, Knox, \& Hansen, 2008; Mohammad et al., 2018). However, identification of the critical E3

345 ligase or ligases for LST-1 protein turnover remains a challenge for the future.

346 Regulation of protein stability as a determining factor in the fate switch from stem cell to

347 differentiation is likely a broadly used mechanism (Werner, Manford, \& Rape, 2017). Although few cases

348 are thoroughly understood, examples exist in flies and human cells in addition to nematodes. In flies,

349 cyclin A protein is downregulated by the Bam-dependent deubiquitinase complex to promote

350 differentiation (Ji et al., 2017), and in human embryonic stem cells, Nanog is downregulated by ERK MAP

351 kinase to promote differentiation (Kim et al., 2014). As more examples are uncovered, the regulation of

352 protein stability may emerge as a ubiquitous mechanism for triggering fate switches.

\section{LST-1 and its role in FBF combinatorial control of stem cell regulation}

355 This work defines LST-1 partnership with the FBF RNA-binding protein as pivotal to the LST-1 self-

356 renewal activity. This remarkable and previously mysterious protein therefore provides an important

357 new window into the FBF combinatorial control of stem cell regulation. Indeed, two FBF partners, LST-1

358 and SYGL-1, drive GSC self-renewal (Shin et al., 2017, this work). Each partner is sufficient, and at least

359 one must be present to maintain stem cells (Kershner et al., 2014). Intriguingly, both full length SYGL-1

360 protein and the LST-1(1-210) self-renewal fragment consist largely of IDRs and are of comparable size. 
361 The SYGL-1 protein also possesses two KXXL motifs though their significance has not yet been tested.

362 Nonetheless, we suggest that LST-1 and SYGL-1 are both trans-acting FBF partners that bring an

363 extensive series of IDRs to their respective complexes. Analogous short, trans-acting RNA regulators may

364 be more common than appreciated.

365 The presence of two IDR-rich FBF partners might reflect simple redundancy but also might have a

366 more interesting role and expand the FBF repertoire for combinatorial control. They are clearly

367 functionally redundant (Kershner et al., 2014), but in favor of individual roles, the LST-1 and SYGL-1

368 amino acid sequences bear no similarity to each other, and some genetic interactions differ between the

369 two (J. L. Brenner \& Schedl, 2016; Shin et al., 2017). Moreover, LST-1 localizes to perinuclear granules

370 while SYGL-1 localizes to smaller cytoplasmic puncta, and the spatial regulation of LST-1 is much tighter

371 than SYGL-1 (Shin et al., 2017). We therefore suggest that additional layers of regulation remain to be

372 discovered. In this light, we note that stem cell maintenance must proceed under widely divergent

373 physiological and environmental circumstances. Study of the factors that orchestrate responses to those

374 circumstances, likely including LST-1 and SYGL-1, provide a tantalizing entrée to the complexities of

375 regulation in metazoans.

\section{MATERIALS AND METHODS}

\section{Nematode strains and maintenance}

379 C. elegans were maintained at $20^{\circ} \mathrm{C}$ on Nematode Growth Medium (NGM) plates spotted with E. coli

380 OP50, following established protocols (S. Brenner, 1974), except: strains containing emb-30(tn377ts)

381 were maintained at $15^{\circ} \mathrm{C}$; and the strain containing the qSi291 tumor transgene was maintained on Ist-

382 1(RNAi) plates (see Germline Tumor Assays section). Wild-type was N2 Bristol strain. See Table S1 for list

383 of strains used in this study. We also used the balancer LGI; LGIII hT2[q/s48] (Siegfried \& Kimble, 2002). 


\section{CRISPR/Cas9 genome editing to generate Ist-1 alleles}

See Table S2 for list of CRISPR-induced alleles, and Tables S4 and S5 for additional details about

387 their generation. We used two CRISPR/Cas9 editing methods to create alleles at the endogenous /st-1

388 locus. Three alleles, Ist-1(q867), Ist-1(q869) and Ist-1(q926), were generated using a DNA-based

389 CRISPR/Cas9 approach with a co-conversion strategy (Arribere et al., 2014; Dickinson, Ward, Reiner, \&

390 Goldstein, 2013). Briefly, the following components were microinjected into wild-type germlines: an Ist-

3911 sgRNA plasmid $(25 \mathrm{ng} / \mu \mathrm{l})$, a repair oligo designed to incorporate the desired lst-1 mutations $(500 \mathrm{nM})$

392 and a plasmid encoding Cas9 (pDD162, $50 \mathrm{ng} / \mu \mathrm{l}$ ) (Dickinson et al., 2013) along with a dpy-10 sgRNA

393 (pJA58, $10 \mathrm{ng} / \mu \mathrm{l}$ ) and repair oligo targeting the $d p y$-10 locus (AF-ZF-827, $500 \mathrm{nM}$ ) (Arribere et al., 2014).

394 Progeny of injected hermaphrodites were visually screened for co-injection marker editing and

395 subsequently screened by PCR and Sanger sequencing for editing at the Ist-1 locus.

396 Other alleles, Ist-1(q895), Ist-1(q1032), Ist-1(q1044), Ist-1(q1060), Ist-1(q1086), Ist-1(q1115), Ist-

397 1(q1119), Ist-1(q1124), Ist-1(q1125) and Ist-1(q1198), were generated using RNA-protein complex

398 CRISPR/Cas9 editing with a co-conversion strategy (Arribere et al., 2014; Paix, Folkmann, Rasoloson, \&

399 Seydoux, 2015). The following were microinjected into wild-type N2 (for q895), JK6154 (for q1125),

400 JK5596 (for q1198) or JK5929 [/st-1(q1004), which we call Ist-1(wt) ${ }^{\text {V5 }}$ for simplicity] (all other alleles): Ist-

4011 crRNAs $(10 \mu \mathrm{M}), d p y-10$ or unc-58 co-CRISPR crRNAs $(4 \mu \mathrm{M})$, and tracrRNA $(13.6 \mu \mathrm{M})$ (all Alt-R ${ }^{\mathrm{TM}}$ from $^{-1}$

402 Integrated DNA Technologies, Coralville, IA), repair oligos encoding the desired Ist-1 mutation (4 $\mu \mathrm{M})$

403 and targeting the respective co-CRISPR locus (1.34 $\mu \mathrm{M})$, and recombinant Cas9 protein (24.5 $\mu \mathrm{M})$.

404 Progeny of injected hermaphrodites were first visually screened for co-injection marker editing and next

405 screened by PCR and Sanger sequencing for editing at the Ist-1 locus. All CRISPR/Cas9-generated alleles

406 were outcrossed with wild-type at least twice prior to experimentation. 


\section{MosSCI to generate Ist-1 transgenes}

See Table S3 for list of transgenes generated for this study, and Table S5 for details about plasmids.

410 The Mos1-mediated Single Copy Insertion (MosSCl) method was used to generate all transgenes

411 (Frøkjær-Jensen, Davis, Ailion, \& Jorgensen, 2012; Frøkjær-Jensen et al., 2008; Frøkjær-Jensen et al.,

412 2014). Briefly, repair plasmids containing the gene of interest flanked by sequence targeting the

413 ttTi5605 insertion site were cloned using the Gibson assembly method (Gibson et al., 2009). The repair

414 plasmids were microinjected at $50 \mathrm{ng} / \mu \mathrm{l}$ together with Mos1 transposase and co-injection marker

415 plasmids into JK4950. At least three successful insertions were isolated and analyzed in our experiments,

416 and we report one representative line in this work. During strain generation and maintenance, Ist-

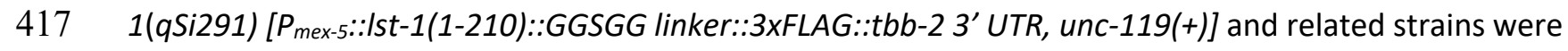

418 grown on Ist-1(RNAi) feeding bacteria to prevent germline tumorigenesis (see RNAi section of Methods).

\section{RNA interference}

RNA interference (RNAi) was performed by feeding as described (Timmons \& Fire, 1998). We used sygl-1 or Ist-1 clones from the Ahringer RNAi library (Fraser et al., 2000) and L4440 plasmid lacking a gene of interest insertion ("empty" RNAi) when an experimental control was required. HT115(DE3)

424 bacteria cultures harboring the RNAi vectors were grown at $37^{\circ} \mathrm{C}$ in $2 x Y T$ media containing $25 \mu \mathrm{g} / \mu \mathrm{l}$

425 carbenicillin and $50 \mu \mathrm{g} / \mu \mathrm{l}$ tetracycline overnight, then were concentrated and seeded onto NGM plates

426 containing 1mM IPTG. Bacteria were induced overnight at RT before plating worms.

\section{DAPI staining}

429 To visualize nuclear morphology, we stained extruded gonads with DAPI (4',6-diamidino-2-

430 phenylindole) as described (S. L. Crittenden, Seidel, \& Kimble, 2017), with minor modifications. Briefly, 431 we dissected animals in PBStw (PBS + 0.1\% (v/v) Tween-20) with $0.25 \mathrm{mM}$ levamisole to extrude gonads, 
432 then fixed at RT for at least 15 minutes in $2 \%(w / v)$ paraformaldehyde diluted in PBStw. Samples were

433 incubated overnight in $-20^{\circ} \mathrm{C}$ methanol, washed with PBStw, then incubated with $0.5 \mathrm{ng} / \mu \mathrm{LAPI}$ in

434 PBStw to stain DNA. We mounted in either Vectashield (Vector Laboratories, Burlingame, CA) or ProLong

435 Gold (Thermo Fisher Scientific, Waltham, MA).

GSC maintenance and masculinization assays

For Figures 1E-F, 2, 3D and Supplementary Figures S1B, S2A, S2E, S4B, mid-L4 hermaphrodites were

439 placed on NGM plates at $20^{\circ} \mathrm{C}$. After 3-4 days, their F1 progeny were assayed for embryo production,

440 which requires a functional germline. All fertile animals made many embryos and young larvae and were

441 scored positive for GSC maintenance. Sterile animals were analyzed further with DAPI staining and

442 compound microscopy. Two types of steriles were found: Mog (for Masculinization of Germline) and Glp

443 (Germline proliferation defective). Mog germlines had a roughly normal size, harbored mitotically

444 dividing GSCs in the distal germline, but made only sperm (no oocytes); Mogs were scored positive for

445 GSC maintenance. Glp steriles had a very small germline made of only a few sperm. In Glp animals, we

446 counted sperm number after DAPI staining and divided by four to estimate germ cell number. We

447 removed sygl-1 in some cases by feeding RNAi and in others by crossing into a sygl-1 loss-of-function or

448 null mutant. For RNAi, strains were plated onto sygl-1(RNAi) plates as mid-L4 hermaphrodites at $20^{\circ} \mathrm{C}$

449 and their F1 progeny were scored for GSC maintenance as described. In the case of Glp germlines, we

450 quantitated the number of germ cells by DAPI staining, counting the number of mature sperm, and

451 dividing by four (since one germ cell differentiates into four sperm).

\section{Progenitor zone size}

454 Progenitor zone (PZ) size was assessed in nematodes staged to 24 hours past mid-L4 at $20^{\circ} \mathrm{C}$.

455 Extruded gonads were DAPI stained and imaged with a confocal microscope (see Microscopy). We 
examined nuclear morphology to determine PZ size, according to convention (Sarah L. Crittenden et al.,

457 2006; Seidel \& Kimble, 2015). Briefly, when germ cells exit the PZ and begin meiotic prophase, their

458 nuclear morphology takes on a distinctive crescent shape (see Figure 4A). We selected a central focal

459 plane in the distal gonad and then counted the number of cells along each edge of the tissue until we

460 reached the distal-most cell with crescent morphology. We counted manually using the FIJI/ImageJ

461 multi-point tool, calling each DAPI-stained nucleus a unique cell row. We averaged the two values from

462 the two edges of the gonad together to determine PZ size.

Immunostaining

We performed immunostaining of extruded gonads as described (S. L. Crittenden et al., 2017) with minor modifications. All strains (except the strain containing the qSi291 tumor transgene, see Germline

467 Tumor Assays section) were grown at $20^{\circ} \mathrm{C}$ and staged to 24 hours past mid-L4 stage, then dissected in 468 PBStw with $0.25 \mathrm{mM}$ levamisole to extrude gonads. Tissue was fixed in $2.5 \%(\mathrm{w} / \mathrm{v})$ paraformaldehyde 469 diluted in PBStw for $10 \mathrm{~min}$, then permeabilized with PBStw $+0.2 \%(\mathrm{v} / \mathrm{v})$ Triton-X for $10-15$ minutes.

470 Samples were blocked for at least 1 hour and not more than 4 hours in $0.5 \%(w / v)$ bovine serum

471 albumin diluted in PBStw, except $\alpha$-FLAG which was blocked in $30 \%(v / v)$ goat serum diluted in PBStw.

472 Next, samples were incubated overnight at $4^{\circ} \mathrm{C}$ with primary antibodies diluted in blocking solution as

473 follows: mouse $\alpha-$ FLAG $^{\circledR}$ (M2, 1:1000, MilliporeSigma, St. Louis, MO), rabbit $\alpha$-GLD-1 (1:100, gift from E.

474 Goodwin), mouse $\alpha$-phospho-histone H3 (Ser10) (6G3, 1:200, Cell Signaling Technology, Danvers, MA),

475 mouse $\alpha$-V5 (SV5-Pk1, 1:1000, Bio-Rad, Hercules, CA), mouse $\alpha$-SP56 (1:200, Gift from Susan Strome,

476 University of California, Santa Cruz). Secondary antibodies were diluted in blocking solution and

477 incubated with samples for at least one hour and not more than 4 hours as follows: Alexa 488 donkey $\alpha-$

478 mouse (1:1000, Thermo Fisher Scientific), Alexa 647 goat $\alpha$-rabbit (1:1000, Thermo Fisher Scientific). To

479 visualize DNA, DAPI was included at a final concentration of $0.5-1 \mathrm{ng} / \mu$ l during a final PBStw wash 
performed after secondary antibody incubation. Samples were mounted in ProLong Gold (Thermo Fisher

481 Scientific) and allowed to cure overnight before imaging. All steps were performed at RT unless

482 otherwise indicated.

smFISH and used at a final concentration of $0.25 \mu \mathrm{M}$. Probe sequences are available by request.

\section{emb-30 assay}

The assay was performed as previously described (Cinquin et al., 2010; Shin et al., 2017) with minor

494 modifications. Briefly, strains were maintained in a programmable incubator at $15^{\circ} \mathrm{C}$ until 36 hours past

$495 \mathrm{~L}$, then transitioned to $25^{\circ} \mathrm{C}$ for an additional 12 hours. Gonads were extruded, fixed, and stained for $\alpha$ -

496 PH3, $\alpha$-GLD-1 and DAPI (see Immunostaining). We imaged gonads by confocal microscopy (see

497 Microscopy). To analyze the images, we used the DAPI channel to determine the "M-phase boundary"

498 between presence and absence of arrested M-phase cells. In cases where a single M-phase cell was

499 found more than three cell rows proximal to all other M-phase cells, that cell was disregarded for

500 determining the boundary. We counted all cells distal to the M-phase boundary, including arrested M-

501 phase cells and cells likely still arrested but not with a typical M-phase morphology, using the multipoint

502 tool in Fiji/ImageJ (Schindelin et al., 2012). Germlines with excessively fragmented distal nuclei were

503 excluded from the counts as cell numbers could not be determined (20-60\% per experiment). 


\section{Germline tumor assays}

To induce ubiquitous expression of LST-1(1-210) using the qSi291 tumor transgene, L4 P0 animals

were transferred from Ist-1 RNAi bacteria to OP50-seeded NGM plates. Experiments were performed at

$50815^{\circ} \mathrm{C}$ to maximize tumor penetrance (Shin et al., 2017). After removal from RNAi, subsequent

509 generations were assayed by dissection microscope and showed increasing tumor penetrance $(n>100$

510 for all): in F1, we observed no animals with tumors in both germline arms; in F2, 60\% had tumors; in F3,

$511 \sim 90 \%$ had tumors. For Figure 6D, we dissected and stained F3 generation L4-staged animals.

\section{Microscopy}

$514 \quad$ All gonad images were taken using a laser scanning Leica TCS SP8 confocal microscope fitted with

515 Photomultiplier (PMT) and Hybrid (HyD) detectors and run with LAS software version 3.3.1 or X

516 (Wetzlar, Germany). A 63x/1.40 CS2 HC Plan Apochromat oil immersion objective was used, except for

517 Figure S2, which used a 40x/1.30 CS2 HC PL APO oil immersion objective. All images were taken using

518 the standard scanner with $400-700 \mathrm{~Hz}$ scanning speed and $100-300 \%$ zoom. To prepare figures, Adobe

519 Photoshop was used to equivalently and linearly adjust contrast among samples to be compared.

\section{Fluorescence quantitation}

Immunostaining quantitation in Figures $\mathbf{3} \mathbf{K}$ and $\mathbf{4 H}$ was performed with Fiji/ImageJ (Schindelin et al.,

523 2012) using images taken under identical conditions across all samples. In Figure 3K, we performed

524 three independent experiments consisting of at least 7 gonads per genotype for a total of at least 21

525 gonads per genotype. In Figure $\mathbf{4 H}$, we performed at least three independent experiments consisting of

526 at least 5 gonads per genotype, with a total of at least 23 gonads per genotype. To collect intensity data

527 from our images, we adapted a workflow from the literature (J. L. Brenner \& Schedl, 2016). First, the 
528 sum of all Z-slices for each gonad was projected onto a single plane. A freehand line, 50 pixels wide and

529 at least $80 \mu \mathrm{m}$ long that bisected the gonad, was drawn manually starting from the distal tip of the

530 tissue. Next, the pixel intensity data for the V5 channel along the line was obtained using the Plot Profile

531 feature. We averaged the raw pixel intensity for at least 5 gonads at every $x$ value to generate an

532 average protein expression plot for each genotype in a given experiment. Next, to adjust for non-specific

533 background staining, we subtracted the average intensity of the respective negative control at each $\mathrm{x}$

534 value from the average protein expression curves. We then normalized each average protein expression

535 curve using the maximum and minimum values of the respective average wild type $\left(/ s t-1\left(w t^{V 5}\right)\right)$ plot.

536 Finally, to generate the plots shown, the adjusted (background subtracted and normalized) protein

537 expression plots for each genotype were averaged among at least three experiments. Standard error at

538 each $\mathrm{x}$ value was calculated among the three independent replicates for each genotype. The number of

539 germ cell diameters (gcd) along the $x$-axis were calculated using a conversion factor of $4.4 \mathrm{gcd} / \mu \mathrm{m}$ (Lee

540 et al., 2016).

541 smFISH quantitation in Figure $\mathbf{5} \mathbf{F}$ was performed similarly to the immunostaining quantitation

542 described above, with minor modifications. After Z-projection, an average gonad-specific background

543 level was also collected and subtracted from the raw values. This was done by using the rectangle tool

544 to create a $2 \mu \mathrm{m}$ square box which was manually placed on the image where no transcripts could be

545 seen by eye. This was repeated for three separate locations along the gonad: one distally within $50 \mu \mathrm{m}$

546 of the distal tip, one centrally between $50-100 \mu \mathrm{m}$ from the distal tip, and one proximally between 100-

$547150 \mu \mathrm{m}$ from the distal tip. For each location, the measure feature was used to collect the average pixel

548 intensity within the $2 \times 2 \mu \mathrm{m}$ box. The values obtained for each location were then averaged together to

549 yield the final background value for the individual gonad. This gonad-specific background value was

550 subtracted from the raw values of the respective gonad and we proceeded with quantitation as

551 described above (i.e. plot profile, averaging, background subtraction, and normalizing). We performed 
552 three independent experiments consisting of at least 9 gonads per genotype for a total of 30 gonads per

553 genotype analyzed. To compare between data sets that were collecting using different zoom factors, we

554 condensed each average RNA expression plot by calculating a rolling average of either 4 or $5 \mathrm{x}$ - and $\mathrm{y}$ -

555 values. After adjustment, the respective $x$-values across all data sets were essentially equal and differed

556 by no more than $0.02 \mu \mathrm{m}$. For smFISH, the genotype of the negative control was Ist-1(q869), which

557 harbors a deletion in the lst-1 locus spanning from $139 \mathrm{bp}$ upstream of the start codon to $228 \mathrm{bp}$

558 downstream of the stop codon. Of note, five of the $40 \mathrm{smFISH}$ probes used were predicted to anneal in

559 the Ist-1(ø) negative control.

561 Yeast two-hybrid

562 Modified yeast two-hybrid assays were performed as described (Bartel \& Fields, 1997). Briefly, LST-1

563 variants were amplified from cDNA and cloned into the Gal4 activation domain plasmid pACT2 using the

564 Gibson assembly method (Gibson, 2009). We also used plasmid pJK2017, which is FBF-2 cDNA (a.a. 121-

565 632) fused to the LexA binding domain in the pBTM116 backbone (Shin et al., 2017). Activation and

566 binding domain plasmid pairs were co-transformed into L40-ura3 strain (MATa, ura3-52, leu2-3,112,

567 his3 200 , trp1 1 1, ade2, LYS2::(LexA-op) ${ }_{4}-H I S 3$, ura3::(LexA-op) ${ }_{8}-$ LacZ) using the LiOAc method (Gietz \&

568 Schiestl, 2007). His3 reporter activity was assayed on synthetic defined medium -Leu-Trp-His plates

569 supplemented with varying concentrations of 3-Amino-1,2,4-triazole (3-AT) (MilliporeSigma) and

570 compared to -Leu-Trp plates as controls. We measured LacZ reporter activity using the Beta-Glo ${ }^{\circledR}$ Assay

571 System following the commercially available protocols and the yeast literature (Promega, Madison, WI)

572 (Hook, Bernstein, Zhang, \& Wickens, 2005) and luminescence was quantitated using a Biotek Synergy H4

573 Hybrid plate reader with Gen5 software (Winooski, VT). A complete list of plasmids used in yeast-two

574 hybrid assays is available in Table S5. 


\section{Western blots}

For Figure 1I, samples were prepared by boiling 50 unstaged adult worms in sample buffer (60 mM

578 Tris $\mathrm{pH} 6.8$, 25\% glycerol, 2\% SDS, $0.1 \%$ bromophenol blue with $700 \mathrm{mM}$ beta-mercaptoethanol). For

579 Figure S4, we grew yeast transformants in -Leu-Trp liquid media and prepared samples by boiling yeast

580 in sample buffer. Subsequent analysis was conducted on a $12 \%$ SDS-PAGE gel and blots were probed

581 with either mouse $\alpha$-V5 (SV5-Pk1, 1:1000, Bio-Rad), mouse $\alpha-H A$ (HA.11, 1:1000, Covance, Burlington,

$582 \mathrm{NC}$ ) or mouse $\alpha$-actin (C4, 1:40,000, MilliporeSigma) followed by donkey $\alpha$-mouse horseradish

583 peroxidase (1:10,000, Jackson ImmunoResearch, West Grove, PA). Immunoblots were developed using

584 SuperSignal ${ }^{\mathrm{TM}}$ West Pico/Femto Sensitivity substrate (Thermo Fisher Scientific) and developed using a

585 Konica Minolta SRX-101A medical film processor (Wayne, NJ). For final figure preparations, contrast of

586 the blot was linearly adjusted in Adobe Photoshop. For Figure 1I, Fiji/ImageJ was used for quantitation.

\section{Statistics}

Where appropriate, statistical analyses are described in figure legends. Homogeneity of variance

590 was established using Levine's test. One-way ANOVA and Tukey's post hoc tests were performed to

591 calculate statistical significance for multiple samples. A two-tailed $t$-test assuming equal variance was

592 performed when comparing two samples. All statistical tests were performed in R and the $p$-value cut

593 off was 0.05.

\section{ACKNOWLEDGEMENTS}

596 We thank Jonathan Doenier, Michael Green, Sarah Jayawardene, Peggy Kroll-Conner, Kimberley

597 Law, Alex Murphy and Brandon Taylor for help generating strains central to this work, as well as Jadwiga

598 Forster, Kyle Krueger and Charlotte Kanzler for technical assistance. We also thank members of the

599 Kimble and Wickens laboratories for insightful discussions, and Sarah Crittenden and Brian Carrick for 
comments on our manuscript. We are grateful to Laura Vanderploeg and Anne Helsley-Marchbanks for

601 assistance with figures and manuscript preparation. We thank Susan Strome (University of California,

602 Santa Cruz) for SP56 antibodies. Some strains used in the study were provided by the Caenorhabditis

603 Genetics Center, supported by the NIH Office of Research Infrastructure Programs (P40 OD010440). J.K.

604 is an Investigator with the Howard Hughes Medical Institute; M.W. is supported by NIH R01GM050942.

605

\section{COMPETING INTERESTS}

607 The authors declare no competing interests.

608

\section{REFERENCES}

610 Ahringer, J., \& Kimble, J. (1991). Control of the sperm-oocyte switch in Caenorhabditis elegans hermaphrodites by the fem-3 3' untranslated region. Nature, 349(6307), 346-348.

612 Arribere, J. A., Bell, R. T., Fu, B. X., Artiles, K. L., Hartman, P. S., \& Fire, A. Z. (2014). Efficient marker-free recovery of custom genetic modifications with CRISPR/Cas9 in Caenorhabditis elegans. Genetics,

615 Austin, Judith, \& Kimble, Judith. (1987). glp-1 is required in the germ line for regulation of the decision between mitosis and meiosis in C. elegans. Cell, 51, 589-599. doi:10.1016/0092-8674(87)901280

618 Bartel, Paul L., \& Fields, Stanley (Eds.). (1997). The Yeast Two-Hybrid System. New York: Oxford University Press.

620 Brenner, J. L., \& Schedl, T. (2016). Germline stem cell differentiation entails regional control of cell fate regulator GLD-1 in Caenorhabditis elegans. Genetics, 202(3), 1085-1103.

623 Brenner, S. (1974). The genetics of Caenorhabditis elegans. Genetics, 77(1), 71-94. 
624 Buchan, Daniel W A, \& Jones, David T. (2019). The PSIPRED Protein Analysis Workbench: 20 years on. Nucleic Acids Research. doi:10.1093/nar/gkz297

626 Calabretta, S., \& Richard, S. (2015). Emerging roles of disordered sequences in RNA-binding proteins. Trends in Biochemical Sciences, 40(11), 662-672. doi:10.1016/j.tibs.2015.08.012

628 Campbell, Z. T., Menichelli, E., Friend, K., Wu, J., Kimble, J., Williamson, J. R., \& Wickens, M. (2012). Identification of a conserved interface between PUF and CPEB proteins. The Journal of Biological Chemistry, 287(22), 18854-18862. doi:10.1074/jbc.M112.352815

631 Chen, W., \& Moore, M. J. (2014). The spliceosome: disorder and dynamics defined. Current opinion in structural biology, 24, 141-149. doi:10.1016/j.sbi.2014.01.009

633 Cinquin, O., Crittenden, S. L., Morgan, D. E., \& Kimble, J. (2010). Progression from a stem cell-like state to early differentiation in the C. elegans germ line. Proceedings of the National Academy of

Crittenden, S. L., Seidel, H. S., \& Kimble, J. (2017). Analysis of the C. elegans germline stem cell pool. Methods in Molecular Biology, 1463, 1-33. doi:10.1007/978-1-4939-4017-2_1

638 Crittenden, Sarah L., Bernstein, David S., Bachorik, Jennifer L., Thompson, Beth E., Gallegos, Maria, Petcherski, Andrei G., ... Kimble, Judith. (2002). A conserved RNA-binding protein controls germline stem cells in Caenorhabditis elegans. Nature, 417, 660-663. doi:10.1038/nature754

641 Crittenden, Sarah L., Leonhard, Kimberly A., Byrd, Dana T., \& Kimble, Judith. (2006). Cellular analyses of the mitotic region in the Caenorhabditis elegans adult germ line. Molecular Biology of the Cell,

644 Dickinson, D. J., Ward, J. D., Reiner, D. J., \& Goldstein, B. (2013). Engineering the Caenorhabditis elegans genome using Cas9-triggered homologous recombination. Nature Methods, 10(10), 1028-1034. doi:10.1038/nmeth.2641 
Dyson, H. Jane. (2016). Making sense of intrinsically disordered proteins. Biophys J, 110(5), 1013-1016. doi:10.1016/j.bpj.2016.01.030

Fraser, Andrew G., Kamath, Ravi S., Zipperlen, Peder, Martinez-Campos, Maruxa, Sohrmann, Marc, \& Ahringer, Julie. (2000). Functional genomic analysis of $C$. elegans chromosome I by systematic

Frøkjær-Jensen, C., Davis, M. W., Ailion, M., \& Jorgensen, E. M. (2012). Improved Mos1-mediated transgenesis in C. elegans. Nature Methods, 9(2), 117-118. doi:10.1038/nmeth.1865

Frøkjær-Jensen, C., Davis, M. W., Hopkins, C. E., Newman, B. J., Thummel, J. M., Olesen, S. P., . . Jorgensen, E. M. (2008). Single-copy insertion of transgenes in Caenorhabditis elegans. Nature Genetics, 40(11), 1375-1383. doi:10.1038/ng.248

Frøkjær-Jensen, C., Davis, M. W., Sarov, M., Taylor, J., Flibotte, S., LaBella, M., . . Jorgensen, E. M. (2014). Random and targeted transgene insertion in Caenorhabditis elegans using a modified Mos1 transposon. Nature Methods, 11(5), 529-534. doi:10.1038/nmeth.2889

Furuta, Tokiko, Tuck, Simon, Kirchner, Jay, Koch, Bryan, Auty, Roy, Kitagawa, Risa, . . Greenstein, David. (2000). EMB-30: An APC4 homologue required for metaphase-to-anaphase transitions during

Gibson, D. G. (2009). Synthesis of DNA fragments in yeast by one-step assembly of overlapping oligonucleotides. Nucleic Acids Research, 37(20), 6984-6990. doi:10.1093/nar/gkp687

Gibson, D. G., Young, L., Chuang, R. Y., Venter, J. C., Hutchison, C. A., 3rd, \& Smith, H. O. (2009). Enzymatic assembly of DNA molecules up to several hundred kilobases. Nature Methods, 6(5), 343-345. doi:10.1038/nmeth.1318 
670 Gupta, P., Leahul, L., Wang, X., Wang, C., Bakos, B., Jasper, K., \& Hansen, D. (2015). Proteasome regulation of the chromodomain protein MRG-1 controls the balance between proliferative fate and differentiation in the C. elegans germ line. Development, 142(2), 291-302. doi:10.1242/dev.115147

674 Hashimoto, H., Hara, K., Hishiki, A., Kawaguchi, S., Shichijo, N., Nakamura, K., ... Sato, M. (2010). Crystal structure of zinc-finger domain of Nanos and its functional implications. EMBO reports, 11(11), 848-853. doi:10.1038/embor.2010.155

677 Hook, Brad, Bernstein, David, Zhang, Beilin, \& Wickens, Marvin. (2005). RNA-protein interactions in the yeast three-hybrid system: affinity, sensitivity, and enhanced library screening. $R N A, 11(2), 227-$ 233.

680 Ji, S., Li, C., Hu, L., Liu, K., Mei, J., Luo, Y., . . Chen, D. (2017). Bam-dependent deubiquitinase complex can disrupt germ-line stem cell maintenance by targeting cyclin A. Proceedings of the National Academy of Sciences of the United States of America, 114(24), 6316-6321. doi:10.1073/pnas.1619188114

684 Jonas, S., \& Izaurralde, E. (2013). The role of disordered protein regions in the assembly of decapping complexes and RNP granules. Genes \& Development, 27(24), 2628-2641. doi:10.1101/gad.227843.113

687 Jones, D. T., \& Cozzetto, D. (2015). DISOPRED3: precise disordered region predictions with annotated protein-binding activity. Bioinformatics, 31(6), 857-863. doi:10.1093/bioinformatics/btu744 that account for the role of GLP-1/Notch signaling in stem cell maintenance. Proceedings of the National Academy of Sciences of the United States of America, 111(10), 3739-3744. doi:10.1073/pnas.1401861111 
693 Kim, S. H., Kim, M. O., Cho, Y. Y., Yao, K., Kim, D. J., Jeong, C. H., . . . Dong, Z. (2014). ERK1 phosphorylates Nanog to regulate protein stability and stem cell self-renewal. Stem cell research, 13(1), 1-11.

Kimble, J. E., \& White, J. G. (1981). On the control of germ cell development in Caenorhabditis elegans. Developmental Biology, 81, 208-219.

Lander, Arthur D, Kimble, Judith, Clevers, Hans, Fuchs, Elaine, Montarras, Didier, Buckingham, Margaret, ... Oskarsson, Thordur. (2012). What does the concept of the stem cell niche really mean today? BMC Biology, 10, 19. doi:10.1186/1741-7007-10-19

701 Lee, C., Sorensen, E. B., Lynch, T. R., \& Kimble, J. (2016). C. elegans GLP-1/Notch activates transcription

Macdonald, L. D., Knox, A., \& Hansen, D. (2008). Proteasomal regulation of the proliferation vs. meiotic entry decision in the Caenorhabditis elegans germ line. Genetics, 180(2), 905-920. doi:10.1534/genetics.108.091553

Menichelli, E., Wu, J., Campbell, Z. T., Wickens, M., \& Williamson, J. R. (2013). Biochemical characterization of the Caenorhabditis elegans FBF • CPB-1 translational regulation complex identifies conserved protein interaction hotspots. Journal of Molecular Biology, 425(4), 725-737.

711 Mittag, T., \& Parker, R. (2018). Multiple Modes of Protein-Protein Interactions Promote RNP Granule Assembly. Journal of Molecular Biology, 430(23), 4636-4649. doi:10.1016/j.jmb.2018.08.005

713 Mohammad, A., Vanden Broek, K., Wang, C., Daryabeigi, A., Jantsch, V., Hansen, D., \& Schedl, T. (2018). Initiation of meiotic development is controlled by three post-transcriptional pathways in 
Moore, K. A., \& Lemischka, I. R. (2006). Stem cells and their niches. Science, 311(5769), 1880-1885. doi:311/5769/1880 [pii]

Paix, A., Folkmann, A., Rasoloson, D., \& Seydoux, G. (2015). High efficiency, homology-directed genome editing in Caenorhabditis elegans using CRISPR-Cas9 ribonucleoprotein complexes. Genetics, 201(1), 47-54. doi:10.1534/genetics.115.179382

Raj, A., van den Bogaard, P., Rifkin, S. A., van Oudenaarden, A., \& Tyagi, S. (2008). Imaging individual mRNA molecules using multiple singly labeled probes. Nature Methods, 5(10), 877-879.

Rosu, S., \& Cohen-Fix, O. (2017). Live-imaging analysis of germ cell proliferation in the C. elegans adult supports a stochastic model for stem cell proliferation. Developmental Biology, 423(2), 93-100.

Schindelin, J., Arganda-Carreras, I., Frise, E., Kaynig, V., Longair, M., Pietzsch, T., . . Cardona, A. (2012). Fiji: an open-source platform for biological-image analysis. Nature Methods, 9(7), 676-682. doi:10.1038/nmeth.2019

Seidel, H. S., \& Kimble, J. (2015). Cell-cycle quiescence maintains Caenorhabditis elegans germline stem cells independent of GLP-1/Notch. eLife, 4, e10832. doi:10.7554/eLife.10832

Siegfried, Kellee, \& Kimble, Judith. (2002). POP-1 controls axis formation during early gonadogenesis in

Shin, H., Haupt, K. A., Kershner, A. M., Kroll-Conner, P., Wickens, M., \& Kimble, J. (2017). SYGL-1 and LST- 
Caenorhabditis elegans germline. Genetics, 181(4), 1249-1260.

doi:10.1534/genetics.108.099440

742 Timmons, L., \& Fire, A. (1998). Specific interference by ingested dsRNA. Nature, 395(6705), 854.

743 Uversky, V. N. (2017). Intrinsically disordered proteins in overcrowded milieu: Membrane-less organelles, phase separation, and intrinsic disorder. Current opinion in structural biology, 44, 1830. doi:10.1016/j.sbi.2016.10.015

Voronina, E., Paix, A., \& Seydoux, G. (2012). The P granule component PGL-1 promotes the localization and silencing activity of the PUF protein FBF-2 in germline stem cells. Development, 139(20),

Wang, Liaoteng, Eckmann, Christian R., Kadyk, Lisa C., Wickens, Marvin, \& Kimble, Judith. (2002). A regulatory cytoplasmic poly(A) polymerase in Caenorhabditis elegans. Nature, 419(6904), 312-

Wang, Y., Opperman, L., Wickens, M., \& Hall, T. M. (2009). Structural basis for specific recognition of multiple mRNA targets by a PUF regulatory protein. Proceedings of the National Academy of Sciences of the United States of America, 106(48), 20186-20191. doi:10.1073/pnas.0812076106

Ward, Samuel, Roberts, Thomas M., Strome, Susan, Pavalko, Frederick M., \& Hogan, Eileen. (1986).

Webster, M. W., Stowell, J. A., \& Passmore, L. A. (2019). RNA-binding proteins distinguish between Monoclonal antibodies that recognize a polypeptide antigenic determinant shared by multiple

761 Weidmann, C. A., Qiu, C., Arvola, R. M., Lou, T. F., Killingsworth, J., Campbell, Z. T., ... Goldstrohm, A. C. 762 (2016). Drosophila Nanos acts as a molecular clamp that modulates the RNA-binding and repression activities of Pumilio. eLife, 5. doi:10.7554/eLife.17096 
bioRxiv preprint doi: https://doi.org/10.1101/657312; this version posted June 3, 2019. The copyright holder for this preprint (which was not certified by peer review) is the author/funder, who has granted bioRxiv a license to display the preprint in perpetuity. It is made available under aCC-BY-NC-ND 4.0 International license.

764 Werner, A., Manford, A. G., \& Rape, M. (2017). Ubiquitin-dependent regulation of stem cell biology. Trends in Cell Biology, 27(8), 568-579. doi:10.1016/j.tcb.2017.04.002

766 Wu, J., Campbell, Z. T., Menichelli, E., Wickens, M., \& Williamson, J. R. (2013). A protein • protein 767 interaction platform involved in recruitment of GLD-3 to the FBF $\bullet$ fem-3 mRNA complex.

$768 \quad$ Journal of Molecular Biology, 425(4), 738-754. doi:10.1016/j.jmb.2012.11.013

769 Zhang, Beilin, Gallegos, Maria, Puoti, Alessandro, Durkin, Eileen, Fields, Stanley, Kimble, Judith, \&

770 Wickens, Marvin P. (1997). A conserved RNA-binding protein that regulates sexual fates in the $C$.

771 elegans hermaphrodite germ line. Nature, 390(6659), 477-484.

772 
bioRxiv preprint doi: https://doi.org/10.1101/657312; this version posted June 3, 2019. The copyright holder for this preprint (which was not certified by peer review) is the author/funder, who has granted bioRxiv a license to display the preprint in perpetuity. It is made available under aCC-BY-NC-ND 4.0 International license.

Figure 1

Haupt et al.

A Ist-1, direct target of niche signaling

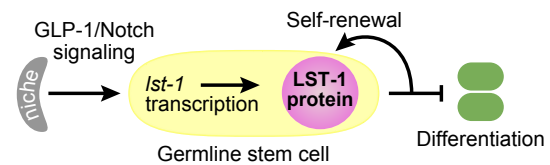

D Ist-1 locus

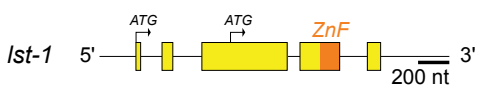

B Hypothesis: LST-1 function

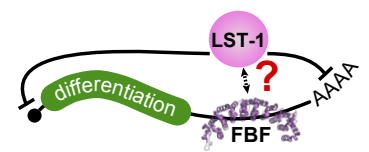

C Hypothesis: LST-1 extent determines GSC pool size

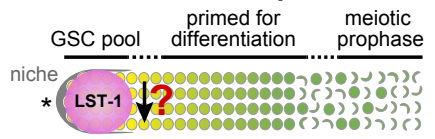

Ist-1 transcripts

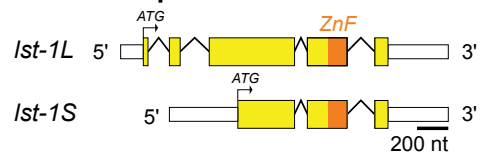

LST-1 protein

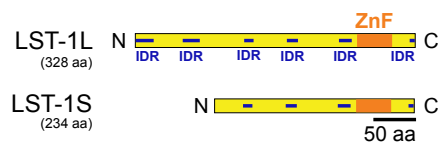

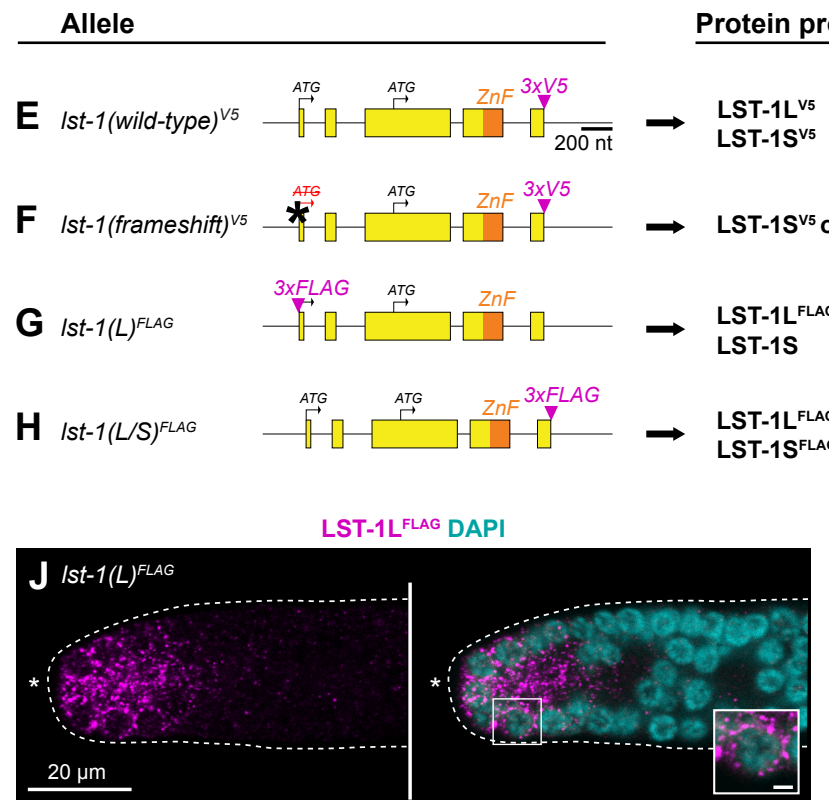

\begin{tabular}{ll} 
GSC maintenance \\
\hline + SYGL-1 & - SYGL-1 \\
\hline
\end{tabular}
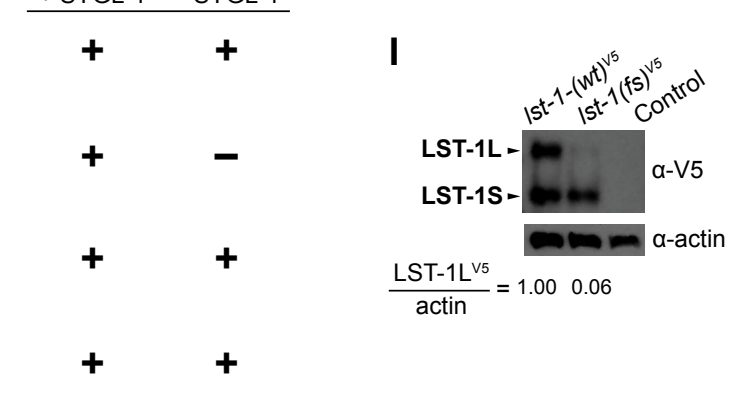

$\frac{\text { LST-1L }^{\mathrm{V} 5}}{\text { actin }}=1.000 .06$

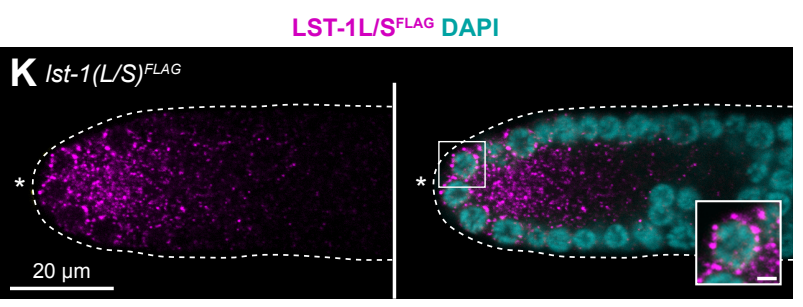

Figure 1. LST-1 isoforms and their role in germline stem cells

A. Niche signaling activates /st-1 transcription in germline stem cells (Kershner et al. 2014; Lee et al. 2016). LST-1 protein drives self-renewal and inhibits differentiation.

B. Hypothesis that LST-1 promotes stemness post-transcriptionally via interaction with FBF, modified from Shin et al. (2017).

C. Hypothesis that LST-1 distribution defines extent of GSC pool in the germline tissue, modified from Shin et al. (2017). LST-1 loss (downward black arrow) launches differentiation.

D. Left panel, the Ist-1 locus encodes two transcripts: Ist-1L(long) and Ist-1S(short). Each transcript (middle panel) produces a respective protein product (right panel). For locus and transcripts: exons (boxes); introns (lines between exons); open reading frame (yellow); single Nanos-related zinc finger ( $\mathrm{ZnF}$ ) (orange); untranslated regions (white boxes); start codons for each protein isoform (black arrows). For protein diagrams: coding sequence (yellow); Nanos-related zinc finger (ZnF) (orange); intrinsically disordered regions (IDR) (dark blue), predicted with DISOPRED3 (Buchan \& Jones, 2019; Jones \& Cozzetto, 2015).

E-H. Left column, alleles to study LST-1L in GSC self-renewal. Conventions as described in Figure 1D; epitope tags (magenta); frameshift mutation (asterisk, ATG to AT $\Delta$ ). Middle column, predicted protein products. Right column, GSC maintenance assay results. We assayed each allele in a sygl-1(ø) mutant background or by sygl-1 RNAi. GSC maintenance was scored positive (+) if the vast majority (>90\%) produced many progeny and negative (-) if all lacked GSCs. See Supplementary Figure S1B for more detailed information.

I. Western blot from whole worm lysate probed with $\alpha-V 5$ to detect epitope-tagged LST-1 protein. LST-1L and LST-1S are visible and labeled with black arrowheads. Actin serves as a loading control, and the ratio between LST-1L and actin was calculated using Fiji/lmageJ. Control for V5 antibody specificity is wild-type N2.

J-K. Representative single confocal Z-slices from middle plane of the distal region of an extruded gonad, stained with $\alpha-F L A G$ to detect the epitope-tagged LST-1 protein. N-terminal 3xFLAG epitope tags only the LST-1L isoform (J), while C-terminal 3xFLAG epitope tags both LST-1L and LST-1S isoforms (K). Dotted line delineates gonad boundary, asterisk marks distal end. Left panels, FLAG staining alone (magenta); right, merge of FLAG (magenta) and DAPI staining (cyan). Inset shows perinuclear staining; scale bar is $1 \mu \mathrm{m}$.

E-K. Alleles indicated are as follows: Ist-1(wildtype $(w t))^{V 5}$ is Ist-1(q1004); Ist-1(frameshift(fs)) ${ }^{V 5}$ is Ist-1(q1198); Ist-1(L) FLAG is Ist-1(q926); Ist-1(L/S)FLAG is Ist-1(q895). 
bioRxiv preprint doi: https://doi org/10.1101/657312; this version posted June 3, 2019. The copyright holder for this preprint (which was not certified by peer review) is the author/funder, who has granted bioRxiv a license to display the preprint in perpetuity. It is made available under aCC-BY-NC-ND 4.0 International license.

Figure 2

Haupt et al.

\section{Endogenous Ist-1 variant allele}

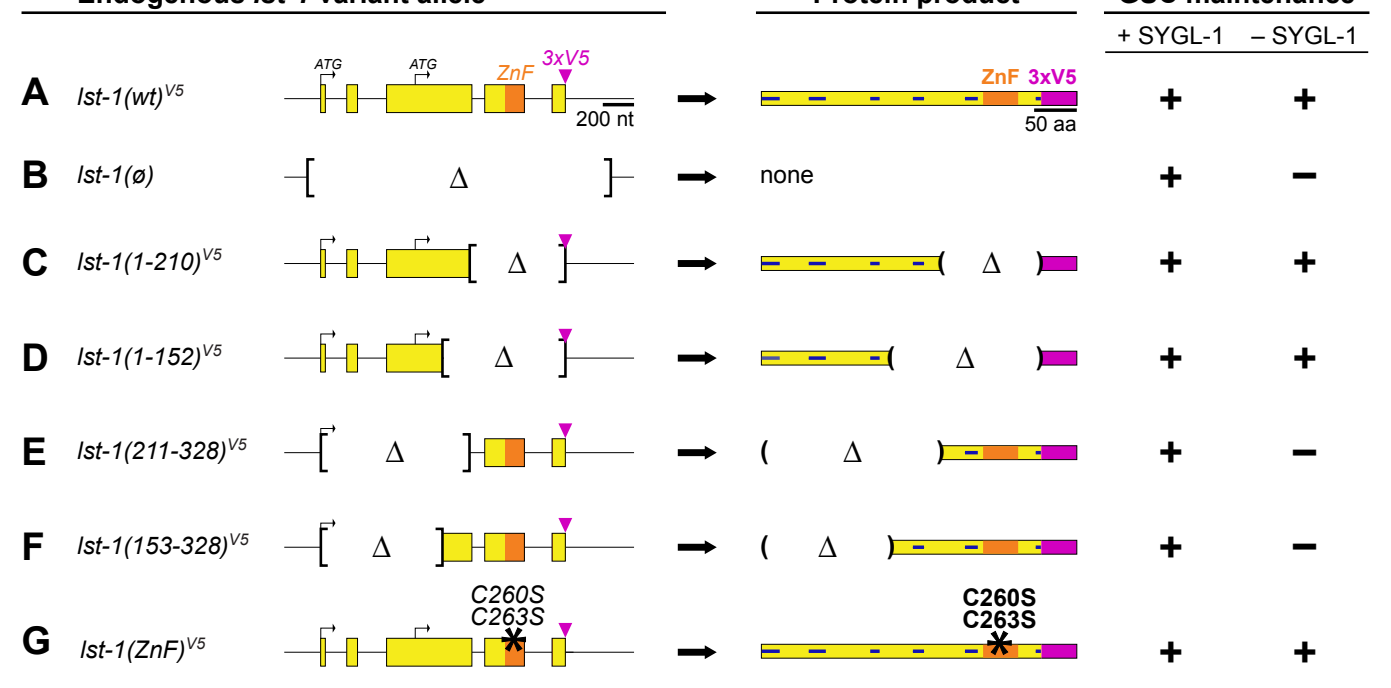

Figure 2. Identification of LST-1 region required for GSC maintenance

A-G. Left column, alleles. Only $/ s t-1 L$ is depicted for simplicity. All variants were created at the endogenous locus in $/ s t-1$ (wild-type) ${ }^{v 5}$, an otherwise wild-type allele carrying 3xV5 at its C-terminus (Figure 1E). Conventions as in Figure 1D-H; internal deletion boundaries (brackets). Middle column, predicted LST-1L protein product. Conventions as in Figure 1D; deletion boundaries (parentheses). For amino acid annotation of variants, see Supplementary Figure S1A. Right column, GSC maintenance assay and scoring as described in Figure 1E-F. For more detailed assay results, see Supplementary Figure S2A. Alleles indicated are as follows: Ist-1(wild-type) ${ }^{v 5}$ is $/ s t-1(q 1004)$; Ist-1(ø), deletion allele removing the entire open reading frame as well as $139 \mathrm{bp}$ upstream of the start codon and 228bp downstream of the stop codon to create a protein null ( $\varnothing)$ is /st-1(q869); Ist-1(1-210) ${ }^{v 5}$ is Ist-1(q1115); Ist-1(1-152) ${ }^{v 5}$ is Ist-1(q1060); Ist-1(211-328) ${ }^{v 5}$ is Ist-1(q1044); Ist-1(153-328) ${ }^{v 5}$ is Ist-1(q1119); Ist-1(ZnF) ${ }^{v 5}$ allele, missense mutations of two zinc finger amino acid residues (black asterisk), is Ist-1(q1032). These residues have been shown by others to be critical for zinc coordination and stabilization of zinc finger architecture (Hashimoto et al. 2010; Weidmann et al. 2016). 
bioRxiv preprint doi: https://doi.org/10.1101/657312; this version posted June 3, 2019. The copyright holder for this preprint (which was not certified by peer review) is the author/funder, who has granted bioRxiv a license to display the preprint in perpetuity. It is made available under aCC-BY-NC-ND 4.0 International license.

Figure 3

Haupt et al.

A Residues in CPB-1 \& GLD-3 required for $\mathrm{FBF}$ interaction

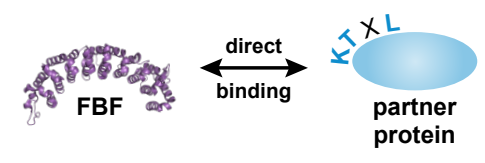

Key residues for FBF binding:

CPB-1 44 KTNLDISVSFL 54

GLD-3 864 KTILEPRARVE 874

C FBF-interaction tested in yeast

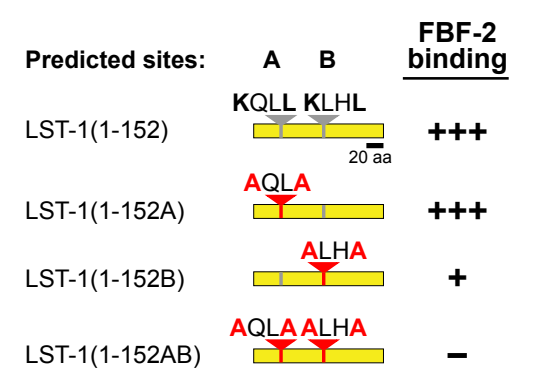

Sperm DAPI
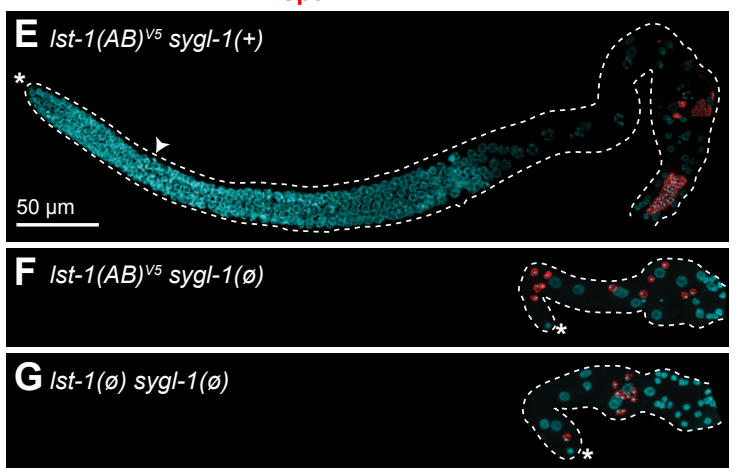

\begin{tabular}{|c|c|c|}
\hline Genotype & $\begin{array}{c}\text { \# GC/animal } \\
\text { (avg } \pm s d)\end{array}$ & $\mathbf{n}$ \\
\hline Ist- $1(w t)^{v_{5}}$ sygl-1(+) $)^{1}$ & $>2000$ & $>100$ \\
\hline $\mid s t-1(w t)^{v 5}$ sygl-1(Ø) & $>2000$ & $>100$ \\
\hline Ist-1(AB) v5 sygl-1(+) & $>2000$ & $>100$ \\
\hline $\mid s t-1(A B)^{v 5}$ sygl-1(ø) & $5 \pm 1$ & 168 \\
\hline Ist-1(Ø) sygl-1(ø) & $5 \pm 1$ & 86 \\
\hline
\end{tabular}

${ }^{1}$ Shin et al., 2017
B Residues in LST-1 predicted to mediate FBF interaction
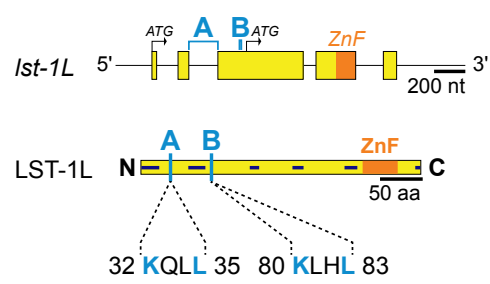

D Biological function tested in nematodes

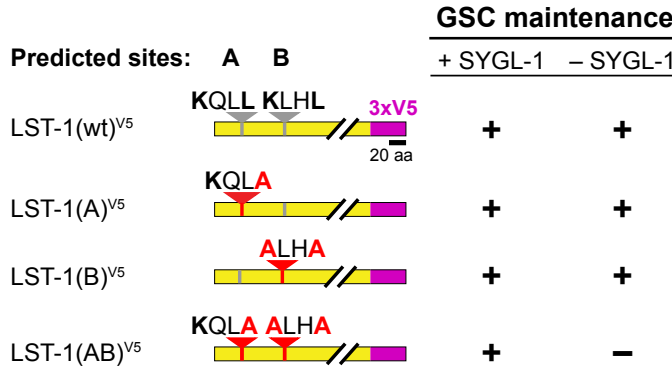

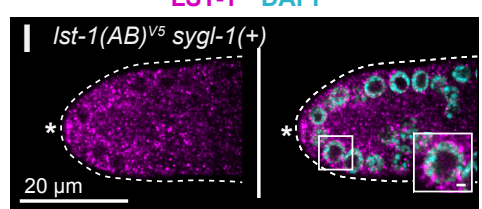
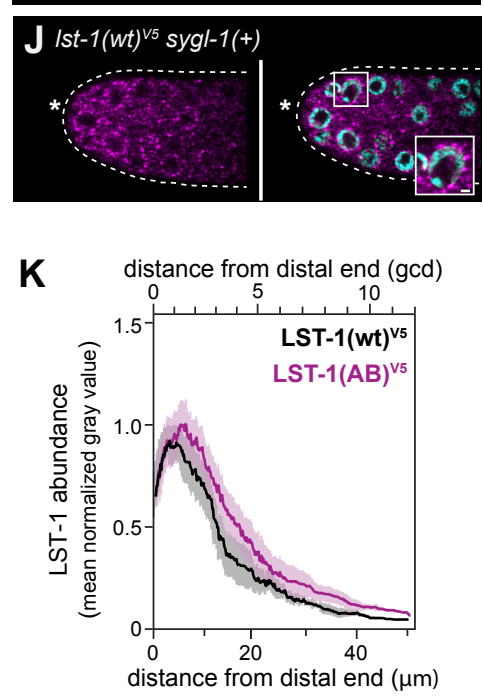

Figure 3. FBF-binding regions in LST-1 and their role in stem cell regulation

A. KTXL motif identified in vitro for two FBF partner proteins, CPB-1 and GLD-3 (Menichelli et al. 2013). PDB ID is 3K5Q (Wang, et al., 2009). B. Two predicted FBF interaction motifs, A and B, in LST-1L-specific sequence. A and B sites (light blue); other conventions as in Figure 1D. Top, positions of $A$ and $B$ in the locus. The nucleotide sequence encoding the $A$ motif spans an intron. Below, positions of $A$ and $B$ in the protein (see also Supplementary Figure S1A).

C. Summary of yeast two-hybrid interactions between FBF-2 and LST-1 A and B motif variants. LST-1 coding sequence (yellow); wild-type motifs (gray); mutant motifs (red); red letters indicate missense mutations. Interaction data is categorized as follows: strong binding $(+++)$, weak binding $(+)$, no binding (-) (see Supplementary Figure S3 for data).

D. Summary of in vivo assays testing LST-1 A and B motif variants for GSC maintenance. Protein conventions as in Figure 1D,3C. GSC maintenance assay and scoring as described in Figure 1E-F. For more detailed results, see Supplementary Figure S4B. 
bioRxiv preprint doi: https://doi.org/10.1101/657312; this version posted June 3, 2019. The copyright holder for this preprint (which was not certified by peer review) is the author/funder, who has granted bioRxiv a license to display the preprint in perpetuity. It is made available under aCC-BY-NC-ND 4.0 International license.

Figure 3

Haupt et al.

E-G. Germline morphology of $/ s t-1(A B)^{v 5}$ allele in the presence and absence of sygl-1. Representative Z-projected confocal images of extruded gonads, immunostained with $\alpha$-SP56 sperm antibody (red) (Ward et al. 1986) and DAPI (cyan). Scale bar in E is valid for all images. Conventions as in Figure 1J-K.

E. Ist-1 $(A B)^{v 5}$ in a strain harboring wild-type SYGL-1. The full germline and progenitor zone (white carat indicates boundary) are both of normal size. F. Ist-1 $(A B)^{v 5}$ in a strain lacking SYGL-1. GSCs are not maintained: the germline is tiny and has only a few differentiated sperm (red). Other DAPI-stained nuclei belong to the somatic gonad.

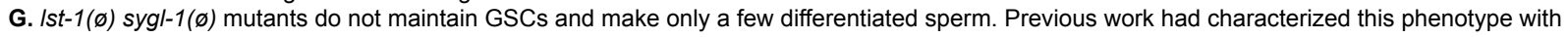
strong loss-of-function alleles (Kershner et al. 2014); here, we report the phenotype using null (ø) alleles.

H. Quantitation and comparison number of germ cells (\# GC) per animal. Total \# GC in $/ s t-1(A B)^{v 5}$ sygl-1(ø) is indistinguishable from Ist-1(ø) sygl-1(ø). I-J. Representative single confocal Z-slices from middle plane of the distal region of an extruded gonad, stained with $\alpha$-V5 to detect epitope-tagged LST-1 protein (magenta) and DAPI (cyan). Scale bar in I is valid for all images. Inset shows perinuclear staining; scale bar is $1 \mu \mathrm{m}$. Conventions as in Figure 1J-K.

I. LST-1 $(A B)^{v_{5}}$ protein is restricted to distal germline, with a distribution similar to wild-type (compare to $\mathbf{J}$ ).

J. LST-1 $(\mathrm{wt})^{\mathrm{V} 5}$ protein is restricted to the distal germline, as previously reported (Shin et al. 2017).

K. Quantitation of LST-1(wt) ${ }^{\mathrm{V} 5}$ and LST-1(AB) $)^{\mathrm{V} 5}$ protein as a function of distance from the distal end, determined by Fiji/lmageJ (see Methods for details). Lines represent the mean value of three independent replicates, each with at least 7 gonads; shading shows standard error. Sample sizes were as follows: LST-1(wt) ${ }^{\mathrm{v} 5}: 3$ replicates with a total of 25 germlines; LST-1(AB) ${ }^{\mathrm{v} 5}: 3$ replicates with a total of 36 germlines. After background from the wild-type N2 control was subtracted, LST-1(wt) ${ }^{\mathrm{v} 5}$ is set to 1.0 at its peak and LST-1(AB) ${ }^{\mathrm{V} 5}$ is normalized to this value. X-axis shows distance from distal end in microns $(\mu \mathrm{m})$ at bottom and in germ cell diameters (gcd) at top.

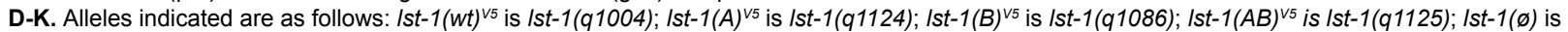
Ist-1(q869); sygl-1(ø) is sygl-1(q828). 
bioRxiv preprint doi: https://doi.org/10.1101/657312; this version posted June 3, 2019. The copyright holder for this preprint (which was not certified by peer review) is the author/funder, who has granted bioRxiv a license to display the preprint in perpetuity. It is made available under aCC-BY-NC-ND 4.0 International license.

Figure 4

Haupt et al.
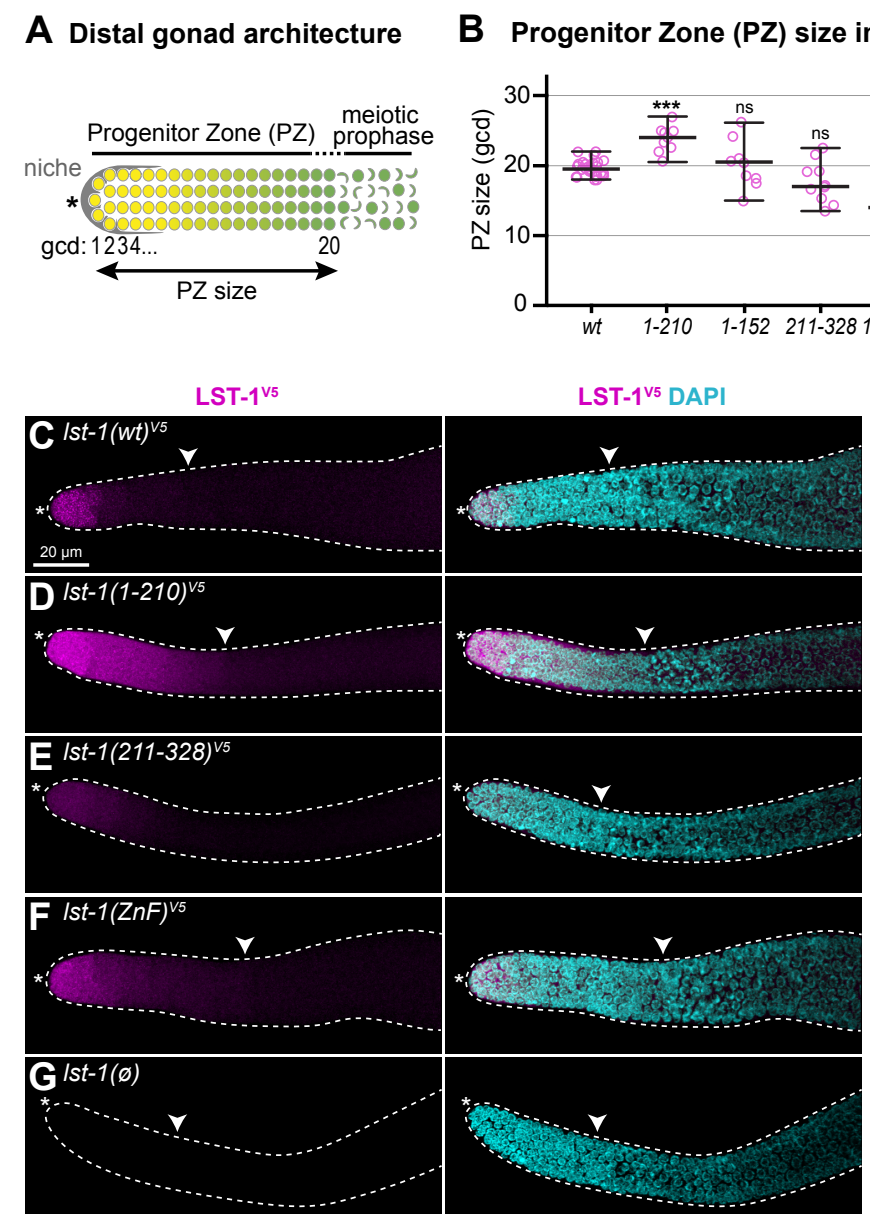

B Progenitor Zone (PZ) size in LST-1 variants

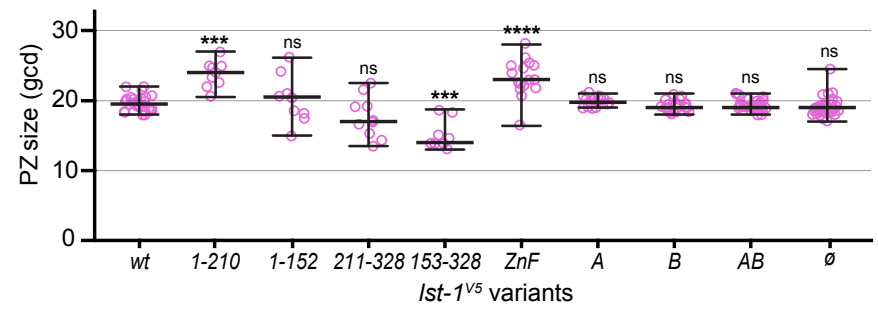

H Protein abundance

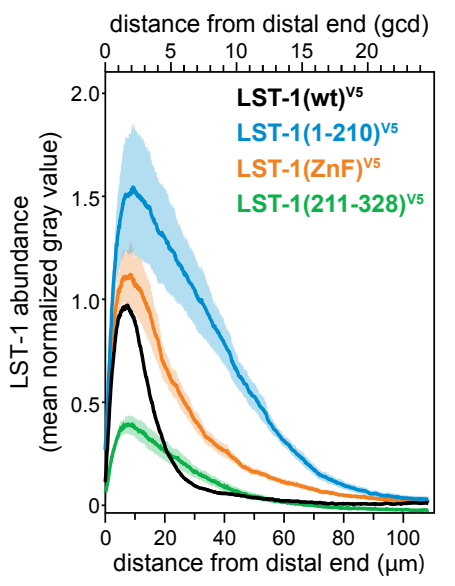

Figure 4. Biological readout and protein expression of LST-1 variants

A. Schematic of progenitor zone (PZ) in the distal gonad. Somatic niche (grey); germline stem cells in naïve state (yellow); GSC daughters primed for differentiation and transitioning toward meiotic entry (graded yellow to green); early meiotic prophase (crescent-shaped). Double-headed arrow marks PZ size, measured by convention (see Methods) in germ cell diameters (gcd) from the distal end.

B. Progenitor zone size in Ist-1 variants measured in average gcd from the distal end. Individual data points are plotted as pink circles; middle line, median; whiskers, minimum and maximum values. $n \geq 9$ for each sample. Asterisks indicate a statistically significant difference by one-way ANOVA with Tukey's post hoc test compared to $/ s t-1(w t)^{v 5:}$ : ‘****' indicates $p<0.0001$, ‘***' indicates $p<0.001$, 'ns' indicates not significant $(p>0.05)$.

C-G. LST-1 variant protein expression in the distal gonad. Representative confocal Z-projections of extruded gonads stained with $\alpha$-V 5 to detect epitope-tagged LST-1 variant protein (magenta) and DAPI (cyan). Left panel, $\alpha$-V5 immunostaining; right panel, merge of $\alpha$-V5 immunostaining and DAPI. Scale bar in A valid for all images. Convention as in Figure 1J-K; white carat marks proximal boundary of progenitor zone.

H. Quantitation of LST-1 protein as a function of distance from the distal end, determined by Fiji/lmageJ (see Methods for details). Each line represents mean values of at least three independent replicates, each with at least 5 gonads; shading shows standard error. Total germlines analyzed were at least 23 per genotype with sample sizes as follows: LST-1(wt) ${ }^{\mathrm{v} 5}: 5$ replicates with a total of 41 germlines; LST-1(1-210 $)^{\mathrm{v5}}: 3$ replicates with a total of 23 germlines; LST-1(ZnF) $)^{\mathrm{v5}}$ : 3 replicates with a total of 27 germlines; LST-1(211-328) $)^{\mathrm{v5}}$ : 3 replicates with a total of 27 germlines. After background from the Ist-1(ø) negative control was subtracted, LST-1 $(\mathrm{wt})^{\sqrt{5}}$ was set to 1.0 at its peak and variants were normalized to this value. X-axis shows distance from distal end in microns $(\mu \mathrm{m})$ on the bottom and in germ cell diameters (gcd) on the top.

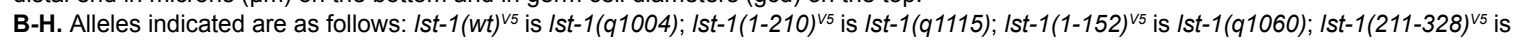

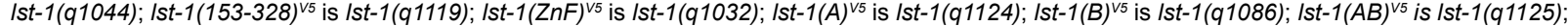
Ist-1(ø) is $/ s t-1$ (q869). 
bioRxiv preprint doi: https://doi.org/10.1101/657312; this version posted June 3, 2019. The copyright holder for this preprint (which was not certified by peer review) is the author/funder, who has granted bioRxiv a license to display the preprint in perpetuity. It is made available under aCC-BY-NC-ND 4.0 International license.

Figure 5

Haupt et al.

\section{A Ist-1 variants}

Ist-1(wt) $)^{\mathrm{V}}$

Ist-1(1-210) ${ }^{v 5}$

Ist-1(ZnF) v5

Ist-1(ø)

Ist-1 RNA (smFISH)
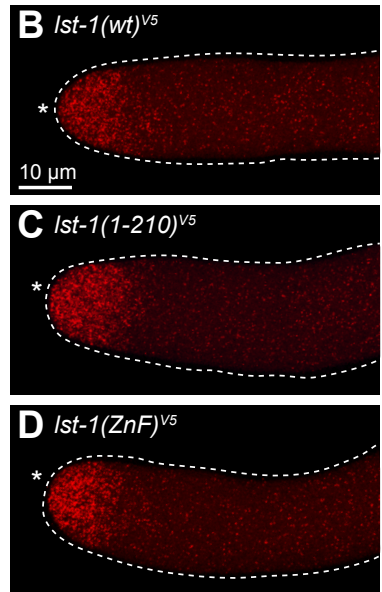

\section{E $\operatorname{lst}-1(\varnothing)$}

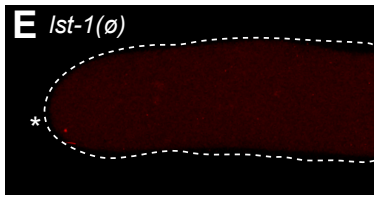

-
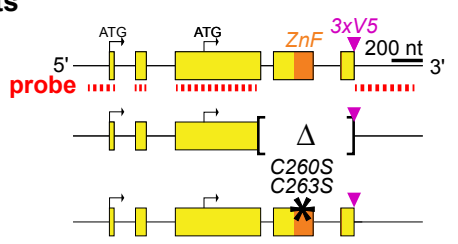

$\Delta$

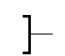

Ist-1 RNA (smFISH) DAPI
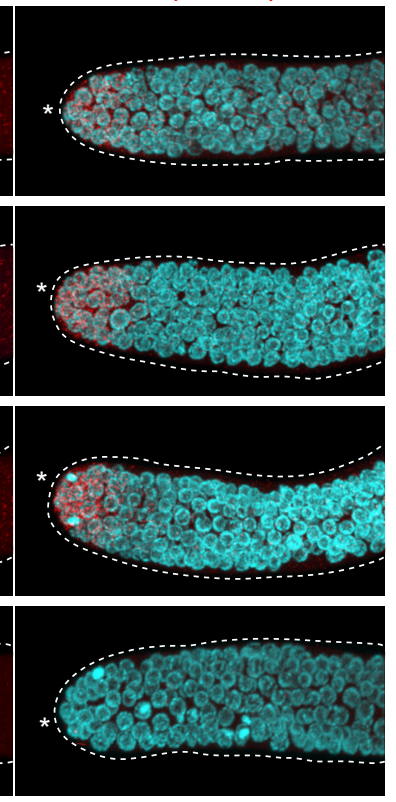

F Ist-1 RNA quantitation

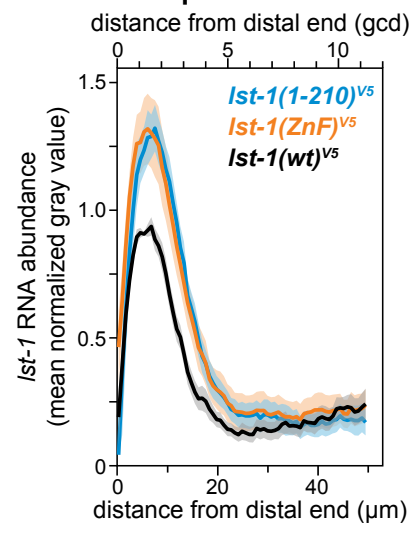

G Comparison of Ist-1 RNA

\& LST-1 protein abundance

distance from distal end (gcd)

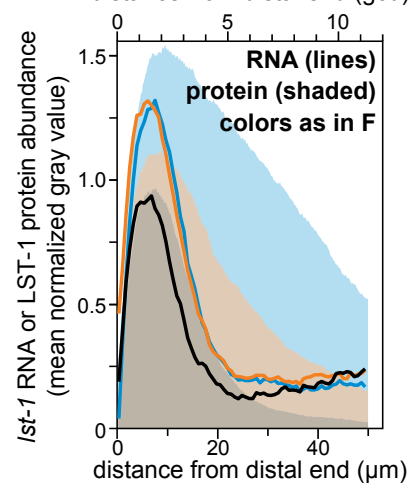

Figure 5. Ist-1 variant RNA expression

A. Ist-1 smFISH probe (red) anneals to sequences present in all strains, except the negative control /st-1(ø). Conventions as in Figure 1D-H.

B-E. Representative Z-projected confocal images of Ist-1 RNA distribution. Extruded gonads were stained for Ist-1 RNA (red) using smFISH and DAPI (cyan). Left panel, Ist-1 RNA; right, merge of Ist-1 RNA and DAPI. Scale bar in B valid for all images. Conventions as in Figure 1J-K.

F. Quantitation of Ist-1 RNA as a function of distance from the distal end, determined by Fiji/ImageJ (see Methods for details). Each line represents mean values of three independent replicates, each with at least 9 gonads, for a total of 30 gonads analyzed per variant; shading shows standard error After background subtraction using $/ s t-1(\varnothing)$, Ist-1(wt) ${ }^{v 5}$ was set to 1.0 at its peak and variants were normalized to this value. Distance from distal end in microns $(\mu \mathrm{m})$ on the bottom and in germ cell diameters $(\mathrm{gcd})$ on the top.

G. Comparison of mean Ist-1 RNA values from Figure 4F (lines) and mean LST-1 protein values from Figure 3F (shading) in the distal germline

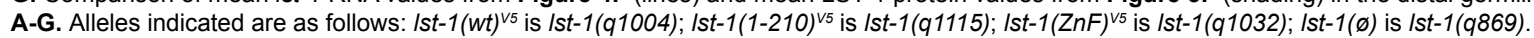


bioRxiv preprint doi: https://doi.org/10.1101/657312; this version posted June 3, 2019. The copyright holder for this preprint (which was not certified by peer review) is the author/funder, who has granted bioRxiv a license to display the preprint in perpetuity. It is made available under aCC-BY-NC-ND 4.0 International license.

Figure 6

Haupt et al.
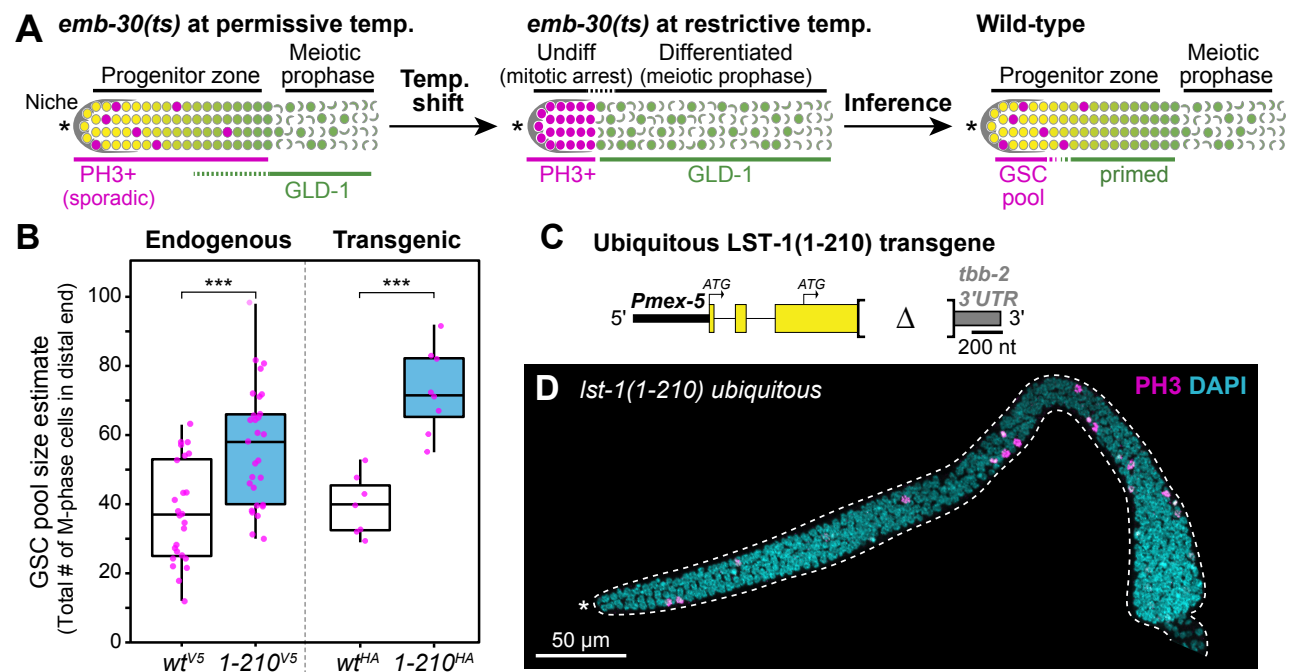

C Ubiquitous LST-1(1-210) transgene
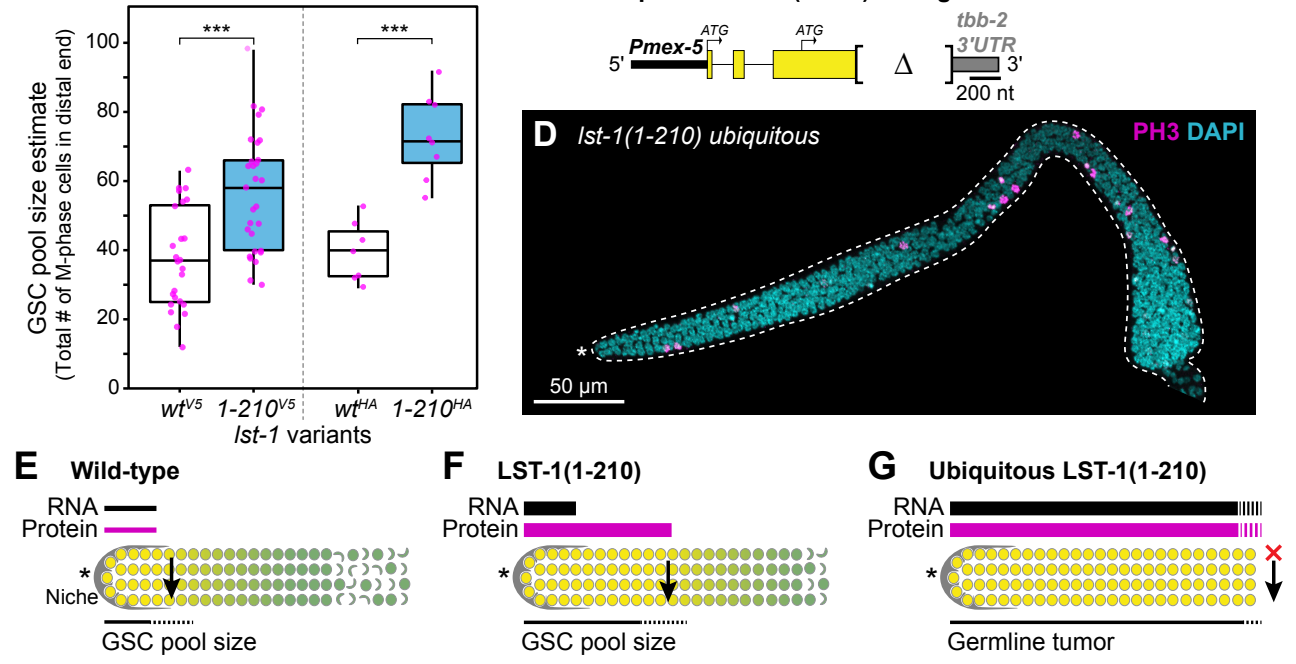

Figure 6. Effect of LST-1 spatial extent on GSC pool size

A. Schematic of emb-30 assay to estimate GSC pool size. The emb-30 gene encodes a component of the anaphase promoting complex (Furuta et al. 2000). In this assay, we used emb-30(tn377ts) to resolve two pools of cells in the PZ, one of which is inferred to be the GSC pool (Cinquin et al. 2010) Left panel: at permissive temperature, the emb-30(ts) progenitor zone appears normal with M-phase germ cells (pink) scattered throughout and GLD-1 levels (green) gradually increasing as germ cells move proximally towards meiotic entry. Middle panel: after shifting an emb-30(ts) mutant from permissive to restrictive temperature, PZ germ cells stop dividing, stop moving proximally and arrest in either of two states. Cells in the distal PZ arrest in mitotic M-phase and express the PH3 M-phase marker, but do not express the GLD-1 differentiation marker. By contrast, germ cells in the proximal PZ enter into meiotic prophase after the emb-30(ts) shift, and express abundant GLD-1 but no PH3. Right panel: we infer from the two pools resolved in emb-30 gonads that the normal progenitor zone possesses a distal pool of naïve germline stem cells and a proximal pool where germ cells are in transit from the stem cell state to overt differentiation. Distal germline cartoon convention as in Figure 4A.

B. Quantitation of GSC pool size, using CRISPR/Cas9-induced endogenous LST-1 variants (left) or LST-1 transgenes (right). After conducting an emb-30 temperature shift, we visualized the distal GSC pool of cells by morphology of DAPI-stained nuclei (see Methods). $p$-values were calculated using a two-tailed $t$-test, assuming equal variance and comparing each LST-1(1-210) variant to its respective LST-1 (wt) control, and '***' indicates $p<0.001$. Endogenous variants were scored in a sygl-1(ø) background; genotypes and sample sizes are as follows: Ist-1(wt) ${ }^{v 5}$ is $/ s t-1$ (q1004) sygl-1(q828); emb-30(tn377ts) $(\mathrm{n}=25)$ and Ist-1(1-210) ${ }^{\mathrm{v}}$ is $/ s t-1$ (q1115) sygl-1(q828); emb-30(tn377ts) $(\mathrm{n}=30)$. Transgenic variants were scored in a sygl-1(+) and genotypes are as follows: Ist-1 (wt) ${ }^{H A}$ is Ist-1 (ok814); qSi22; emb-30(tn377ts) $(\mathrm{n}=7)$ and Ist-1(1-210 ${ }^{\mathrm{HA}}$ is Ist-1(ok814); qSi300; emb-30(tn377ts) ( $\mathrm{n}=8)$.

C. Schematic of MosSCI transgene driving ubiquitous germline expression of LST-1(1-210). Aberrant regulation was conferred with the mex-5 promoter (black) and the tbb-2 3'UTR (gray). LST-1(1-210) is fused C-terminally to GGSGG linker::3xFLAG (not shown).

D. Representative Z-projected confocal image of germline tumor driven by the single copy transgene $q$ Si291[Pmex-5::LST-1(1-210)::GGS-

GG::3xFLAG::tbb-2 3' UTR] (C) in an Ist-1 (ok814) background to eliminate endogenous LST-1. Extruded gonad was stained with a-PH3 (magenta) to visualize cells in M-phase and DAPI (cyan). Conventions as in Figure 1J-K.

E-G. Schematics illustrating the effects of LST-1(1-210) expression on GSC pool size. Ist-1 RNA (black) and LST-1 protein (magenta) expression is shown above, where line thickness correspond to quantity and line length corresponds to the extent of the expression. Below, the resultant phenotypic effects on the GSC pool size are indicated. The location of the switch from stem cell fate to differentiation, which corresponds to LST-1 protein expression, is indicated with a black arrow. Distal germline cartoon convention as in Figure 4A.

E. Wild-type: Ist-1 RNA and LST-1 protein are both restricted to the distal germline and the GSC pool size is similarly restricted.

F. LST-1 (1-210): Ist-1 (1-210) RNA slightly more abundant than in wild-type, but still restricted to the distal germline (from Figure 4). By contrast, LST-1(1-210) protein is considerably more abundant than wild-type and expanded proximally (from Figure 3). GSC pool expands correspondingly (from Figure 5).

G. Ubiquitous LST-1(1-210): major expansion of LST-1 leads to germline tumor formation (from Figure 5). The switch to differentiation fails to occur $($ red X). 
bioRxiv preprint doi: https://doi org/10.1101/657312; this version posted June 3, 2019. The copyright holder for this preprint (which was not certified by peer review) is the author/funder, who has granted bioRxiv a license to display the preprint in perpetuity. It is made available under aCC-BY-NC-ND 4.0 International license.

Figure 7

Haupt et al.

A

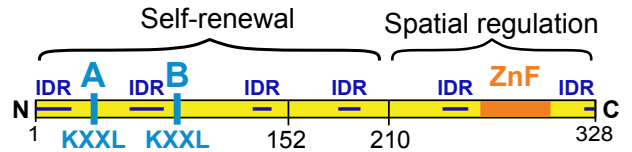

B

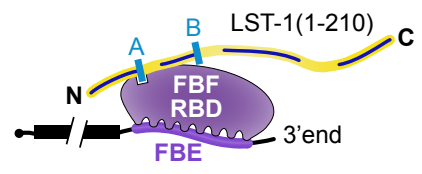

E

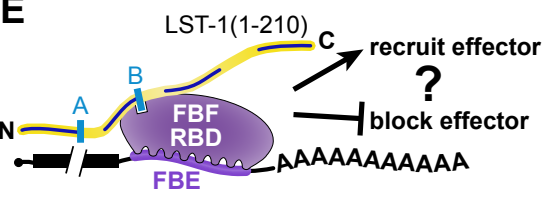

C

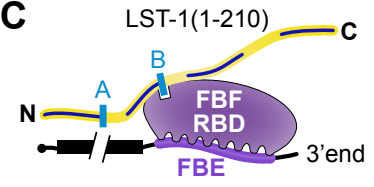

F yPuf3 $\mathrm{N}$-terminal tail

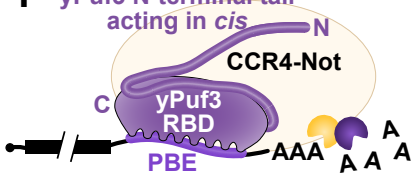

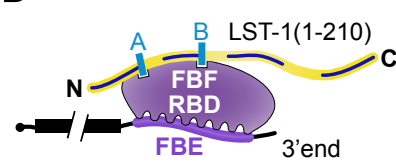

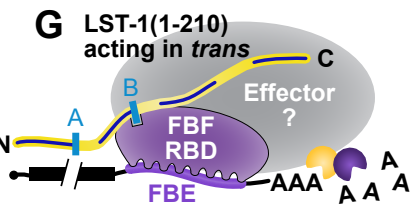

Figure 7. LST-1 molecular function: summary and speculation

A. LST-1 protein possesses one region responsible for self-renewal and another region that restricts its spatial expression. The LST-1 self-renewal region is composed largely of intrinsically disordered regions (IDR) and harbors the two KXXL motifs $A$ and $B$ that mediate interaction with the FBF RNA-binding protein. Conventions as in Figure 1D, 3B.

B-D. Speculation about LST-1-FBF complex formation. The A and B motifs for FBF binding are functionally redundant, which means that complex formation can rely on either the A motif only (B) or the B motif only (C). Formation of these A-specific and B-specific complexes may be subject to differential regulation or offer distinct platforms for recruitment of effectors. LST-1-FBF complexes may also form via interaction with both A and B motifs (D), which may provide additional possibilities for regulation and function.

E-G. Proposals for LST-1-FBF complex function.

E. LST-1-FBF may enhance or inhibit recruitment of an effector.

F. Possible analogy with model for yeast Puf3p, whose N-terminal tail recruits the CCR4-Not complex and promotes its deadenylase activity (modified from Webster et al. (2019).

G. LST-1 IDRs or small linear motifs not yet identified may function in trans to recruit an effector. 